\title{
A atuação do Fed antes e depois do estouro da bolha imobiliária: discricionariedade e mandato de bancos centrais em contexto de desregulamentação financeira ${ }^{1}$
}

\author{
Olivia Bullio $^{2}$ \\ Daniel Nicolau Ferrara ${ }^{3}$ \\ Patrícia Cunha ${ }^{4}$ \\ Carlos Eduardo Carvalho ${ }^{5}$
}

\section{Resumo}

A atuação do Federal Reserve System - Fed - durante a formação e estouro da bolha imobiliária mostra as dificuldades de um banco central em processos financeiros de grande magnitude. O Fed foi leniente com o desenvolvimento da bolha, por considerar que a alta do preço dos imóveis ajudava a reduzir os riscos de instabilidade financeira gerados pelas crises de 2000-2002. Quando a crise do mercado subprime se tornou aguda, em setembro de 2008, o Fed atuou agressivamente como emprestador de última instância, expandindo a base monetária para conter os riscos de inadimplência generalizada no mercado interbancário. Nos dois momentos, o Fed agiu com pragmatismo e discricionariedade, contrariando as teses dominantes do "Novo Consenso", mas foi "prisioneiro" dessas teses e dos interesses do mercado financeiro: a tese de que a desregulamentação dos mercados favorece a sociedade inibiu iniciativas intervencionistas para restringir as inovações financeiras no mercado imobiliário; a tese de que o mandato da Autoridade Monetária deve ser a estabilidade de preços contribuiu para a leniência com os riscos crescentes nos mercados financeiros.

Palavras-chave: Federal Reserve; Política monetária; Crise subprime; Desregulamentação financeira.

\section{Abstract}

The Fed's actions before and after the housing bubble burst: discretion and mandate of central banks in an environment of financial deregulation

The Fed's actions during the development and burst of the US real estate bubble highlight a Central Bank's dilemma when facing a financial process of great magnitude. During the bubble's development and growth, the Fed was lenient since it considered that the increase in real estate prices

(1) Trabalho recebido em 9 de novembro de 2009 e aprovado em 2 de março de 2009. Desenvolvido no Grupo de Pesquisas em Moeda, Finanças e Desenvolvimento Econômico, do Programa de Pós-Graduação em Economia da Pontifícia Universidade Católica de São Paulo - PUC/SP. Os autores agradecem as leituras e comentários dos integrantes do Grupo Andrea Lucchesi (mestre pelo Programa) e Marcelo Balloti Monteiro (mestrando pelo Programa). Os comentários e sugestões de um parecerista anônimo desta revista foram de grande relevância. Quaisquer erros ou omissões ainda presentes são de inteira responsabilidade dos autores.

(2) Doutoranda em Economia no Instituto de Economia/Unicamp, Campinas, SP, Brasil. E-mail: oliviabullio@hotmail.com.

(3) Mestre em Economia pela PUC, São Paulo, SP, Brasil. E-mail: daniel.ferrara@gmail.com.

(4) Professora do Departamento de Economia da PUC, São Paulo, SP, Brasil. E-mail: paticunha@uol.com.br.

(5) Professor do Departamento de Economia da PUC, São Paulo, SP, Brasil. E-mail: cecarv@uol.com.br.

Economia e Sociedade, Campinas, v. 20, n. 2 (42), p. 329-364, ago. 2011. 
helped reduce the risk of financial instability brought on by the financial crisis from 2000 to 2002 . When the subprime crisis surfaced, the Fed started to act vigorously as a lender of last resort, with a vigorous expansion of the monetary basis in order to defend the system from the risk of a widespread default in the interbank market. In both cases the Fed was pragmatic and discretionary, and did not follow the mainstream thesis in economics analysis, the so called "New Monetary Consensus". However, at the same time, the US Central Bank is a "prisoner" of these thesis and of the financial interests that help it sustain them: the thesis that the financial market's deregulation benefits the entire society inhibited interventionist actions that would have restrained the new financial instruments in the housing market and the thesis that the main goal of the Monetary Authority should be price stability contributed to the leniency with the increasing risks in the financial markets.

Keywords: Federal Reserve; Monetary policy; Subprime crisis; Financial deregulation.

JEL E58; E52; G21; G28.

\section{Introdução}

O artigo analisa a atuação do Federal Reserve System - Fed - diante da bolha imobiliária nos anos recentes nos EUA. A análise destaca dois períodos: a formação da bolha, em especial a partir das crises de 2000-2002, e a reação ao estouro da bolha, principalmente depois da eclosão da crise financeira aguda que se seguiu à quebra do Lehman Brothers, em setembro de 2008. O interesse maior é analisar as dificuldades de ação de um banco central (BC) frente a processos financeiros de grande magnitude, conceito em que se incluem bolhas especulativas intensas e prolongadas e ameaças de crises bancárias sistêmicas. O caso do Fed é particularmente relevante nesse sentido.

O Fed passou da leniência durante a formação da bolha para o intervencionismo exacerbado, com atuação intensa como emprestador de última instância, após a decisão de deixar quebrar o Lehman Brothers. A partir desse momento, o Fed agiu com pragmatismo e discricionariedade, como em outros episódios de instabilidade financeira nas últimas décadas. Dessa vez, contudo, essa mudança brusca seguiu-se aos anos de predomínio das teses que compunham o chamado Novo Consenso. Pode-se argumentar que o Fed, apesar da disposição para agir de forma pragmática, foi leniente com a formação da bolha, em grande medida por influência dessas concepções e dos interesses que as sustentam, em especial dos mercados financeiros. No período de formação da bolha, a ação do Fed foi inibida pelo argumento de que a desregulamentação dos mercados financeiros favorece toda a sociedade, o que descartava a adoção de medidas "intervencionistas", voltadas para restringir as práticas financeiras "inovadoras" no mercado de imóveis. Ao mesmo tempo, a leniência diante da bolha foi estimulada pela tese de que o único mandato da Autoridade Monetária deve ser a estabilidade de preços, o que desaconselhava elevações mais fortes dos juros, já que não havia pressões inflacionárias relevantes nos índices de preços tradicionais. Para os mercados financeiros, era também interessante que o BC tivesse como objetivo principal a inflação, como mostra Cintra (2000, p. 188): 
A gestão de estoques de ativos financeiros fica submetida a uma grande vulnerabilidade das taxas de juros às expectativas de inflação, a fim de manter um retorno real positivo. A taxa de inflação constitui uma ameaça permanente de desvalorização da massa de riqueza financeira. O sistema torna-se intrinsecamente 'deflacionista': a inflação é um tumor que precisa ser eliminado, estabelecendo um viés deflacionista nas políticas macroeconômicas.

Nos primeiros anos do século XXI, o Fed se defrontou com dilemas difíceis de equacionar e que preferiu não enfrentar. A estabilidade financeira estava ameaçada pelos efeitos do estouro da bolha no mercado de ações de alta tecnologia em 2000 e pelo temor de que ocorresse uma forte deflação de ativos, o que recomendava uma política monetária cautelosa e acomodatícia, com juros baixos e tolerância em relação à expansão do crédito. Ao mesmo tempo, cresceu a percepção de que o aquecimento do mercado imobiliário indicava a formação de uma nova bolha, mas esta foi vista como favorável ao objetivo de superar a ameaça de instabilidade financeira sem ameaçar a estabilidade de preços, além de favorecer o crescimento da atividade econômica. Dessa forma, ficava difícil acionar o único instrumento disponível, a taxa de juros, inadequada para frear uma bolha em um mercado específico sem o concurso de outras medidas restritivas. Há elementos para afirmar que o determinante principal da leniência com a bolha foi a preocupação com a estabilidade do sistema financeiro após a crise de 2000-2002, e não com o emprego, apesar de esse argumento ter sido invocado diversas vezes nas atas do $\mathrm{FOMC}^{6}$ como parte do duplo mandato do Fed - estabilidade de preços e emprego.

Quando a bolha estourou, por fim, o Fed se viu arrastado para agir ativamente como emprestador de última instância, sem que houvesse referências claras sobre como atuar dessa forma, uma vez que o tema fora afastado das discussões monetárias nos anos anteriores. Restou o pragmatismo de sempre e o Fed passou a improvisar instrumentos e iniciativas diversas para frear a propagação da crise e preservar a estabilidade do sistema financeiro, expandindo a base monetária de forma agressiva.

Blanchard; Dell'Ariccia e Mauro (2010) afirmam que a crise subprime ${ }^{7}$ questionou o que os acadêmicos e os policymarkers pensavam ser a maneira correta para se fazer política monetária. Achava-se que a regulação estaria fora da alçada da política monetária. Apesar do Novo Consenso estar restrito à academia, acabou por influenciar a forma como os bancos centrais atuavam:

(6) O FOMC é o comitê do Fed responsável pelas operações de open market e pela definição da meta de taxa de juros para os títulos federais. É formado por 12 membros, sendo sete membros do Board of Governors, o presidente do Fed e mais quatro presidentes dos onze Federal Reserve Banks regionais, que se revezam e participam das reuniões do FOMC por um ano.

(7) O mercado de crédito hipotecário subprime é aquele em que os financiamentos são fornecidos para tomadores de crédito com alta probabilidade de não pagamento.

Economia e Sociedade, Campinas, v. 20, n. 2 (42), p. 329-364, ago. 2011. 
[...] we thought of monetary policy as having one target, inflation, and one instrument, the policy rate. [...] Admittedly, these views were more closely held in academia: policymakers were often more pragmatic. Nevertheless, the prevailing consensus played an important role in shaping policies and the design of institutions (Blanchard; Dell'Ariccia; Mauro, 2010, p. 3, grifo nosso).

Dessa forma, a crise ampliou os termos restritos em que o Novo Consenso colocou o debate sobre as funções da Autoridade Monetária sobre os objetivos que deve perseguir e os instrumentos que pode e deve acionar para atingi-los, em especial em dois temas cruciais para os BCs: i) a atuação como emprestador de última instância e ii) o comportamento frente a processos de formação de bolhas de ativos.

O artigo apresenta, de início, o quadro teórico em que devem ser tratados esses temas e. em seguida, analisa os posicionamentos do Fed durante a formação da bolha e depois da eclosão da crise. Para tanto, está estruturado em quatro seções, além dessa introdução. A primeira seção destaca a necessidade de analisar a ação do Fed como parte dos processos de instabilidade inerente às economias capitalistas e a necessidade de retomar a discussão da função de emprestador de última instância dos bancos centrais. Nesta seção, também se analisa o debate em torno de que ações um BC deve tomar frente a uma bolha. A segunda seção discute a percepção que o Fed desenvolveu sobre a formação da bolha no mercado imobiliário. Com base na análise das manifestações contidas nas atas das reuniões de seu Comitê de Política Monetária, defende-se que Alan Greenspan tinha conhecimento do que estava ocorrendo no mercado de ativos e que evitou a adoção de medidas destinadas a conter o processo em curso. Na terceira seção, analisa-se a atuação do Fed depois que a crise estourou, quando a única solução encontrada foi atuar com instrumentos novos, discricionários e intervencionistas. Buscou-se apresentar esses novos instrumentos pela análise do balance sheet do Fed de setembro de 2007 a setembro de 2009. Na última, os comentários finais.

\section{Referências para a análise dos dilemas e das condutas adotadas pelo Fed}

A atuação do Fed diante da formação e do estouro da bolha deve ser analisada dentro dos desafios colocados para a Autoridade Monetária pela instabilidade financeira em dois aspectos principais: os problemas da atuação como emprestador de última instância e as possibilidades de atuação diante da formação e desenvolvimento de bolhas especulativas. Estas questões estão desenvolvidas nas duas subseções a seguir.

\subsection{A função de emprestador de última instância}

Até o início da crise subprime, em agosto de 2007, a principal preocupação declarada pelos bancos centrais era a estabilidade de preços. De acordo com o Novo Consenso, o banco central deve ser independente e agir 
pautado por regras, com uma meta intermediária de taxa de juros. A estabilidade financeira, também função da Autoridade Monetária, estaria garantida com a prática de políticas macroeconômicas condizentes com taxas de inflação baixas: "The Federal Reserve vigorously promotes financial stability because of the intimate connection between a stable financial system and solid macroeconomic performance" (Mishkin, 2007b, p. 1). De acordo com essa visão, as regras de supervisão prudencial e a autorregulação dos mercados garantiriam a estabilidade do sistema financeiro nas economias maduras. Com isso, o papel do banco central como emprestador de última instância praticamente desapareceu da literatura convencional, como se não precisasse ser destacada dentre as ações usuais do BC.

Esse ocultamento, porém, não implicava que essa função fosse excluída do leque de competências dos BCs, como reconheceu Fischer (1999, p. 86): "While there is considerable agreement on the need for a domestic lender of last resort, some disagreements persist about what the lender of last resort should do". O surpreendente é que, apesar de uma manifestação de dúvida tão clara, o debate sobre o emprestador de última instância virtualmente desapareceu da literatura econômica do Novo Consenso, no que se refere às economias centrais ${ }^{8}$.

A concepção clássica do emprestador de última instância é a de Bagehot, na qual o banco central fornece crédito a bancos que se mostram saudáveis, mas que, devido a alguma crise, não encontram liquidez no mercado. Um tomador saudável é aquele que pode oferecer títulos como garantia que, apesar de seguros, não podem ser vendidos no mercado devido à deflação de ativos provocada pela própria crise. As taxas de juros, na concepção de Bagehot, deveriam ser punitivas, a fim de prevenir o risco moral (Aglietta, 2004).

Contudo, quando a crise se torna crônica, a falta de liquidez no mercado impossibilita a formação de preço dos ativos. Assim, como o BC pode aceitar um colateral que não tem seu preço formado pelo mercado? Neste cenário, há alta probabilidade de insolvência dos bancos, pois não se sabe o valor dos ativos que essas instituições têm em seus balanços. Esse ponto é destacado por Goodhart (1987). Para ele, como o banco central é responsável pela estabilidade do sistema bancário como um todo, deve emprestar mesmo aos bancos insolventes, uma vez que a crise de confiança pode fazer com que não seja possível fazer a distinção entre bancos ilíquidos e insolventes.

Em 2008, o Fed agiu na linha de Goodhart, em especial depois da quebra do Lehman Brothers, e deu crédito não apenas para bancos ilíquidos e solventes. Além de instituições bancárias insolventes, instituições não bancárias, como

(8) Atraiu mais a atenção a discussão sobre a necessidade de um prestamista internacional para lidar com as crises financeiras dos países emergentes. Estes, como ainda possuem sistemas financeiros menos desenvolvidos, instituições debilitadas e informações pouco transparentes estão sujeitos a crises que podem, via efeito contágio, se alastrar rapidamente para outros países (Fischer, 1999; Mishkin, 2007b). 
bancos de investimento, seguradoras e até mesmo empresas, foram socorridas com empréstimos. Como a precificação dos mercados de títulos abalou-se seriamente, o Fed não tinha mecanismos para verificar quais garantias eram boas ou não.

Permanece em aberto a discussão sobre os motivos que levaram o Fed a não socorrer o Lehman Brothers, decisão que colocou a crise financeira em patamar agudo, com a percepção de risco exacerbada, a ponto de paralisar o sistema interbancário dos EUA. A justificativa apresentada pelo Fed para não socorrer o Lehman Brothers foi que os agentes estavam cientes de que o banco apresentava problemas e tiveram tempo para tomar suas precauções (Bernanke, 2008b). A direção do Fed alegou também que o Lehman Brothers foi incapaz de apresentar o nível mínimo de garantias, embora não se saiba o que seria esse mínimo nem se outros bancos socorridos haviam atendido a esse parâmetro. Vale registrar que a falência do Lehman provocou muitas especulações de que haveria conflito de interesse entre o então secretário do Tesouro, Henry Paulson, exGoldman Sachs, e o resgate do Lehman. É difícil compreender porque o Bear Stearns foi socorrido 7 meses antes e o Lehman não. O jornal New York Times ("Paulson's calls to Goldman tested ethics", 8 ago. 2009) relata o possível conflito de interesse envolvido no episódio quando congressistas o questionaram sobre sua atuação à época.

\subsection{A hipótese de instabilidade financeira de Minsky e o cenário da formação e estouro da bolha}

$\mathrm{Na}$ análise da formação da bolha e nas medidas tomadas pelo Fed, verifica-se que falta ao mainstream fundamentação teórica para pensar em formas eficientes para lidar com o problema. Para esta linha de pensamento, a crise de liquidez, primeira manifestação de uma crise financeira profunda, é sempre originada por um choque sobre um sistema inerentemente estável. Mishkin (2007b, p. 2) identifica quatro tipos de choques que deflagram a crise:

The first type, and the one that has been the catalyst of many past crises, is a sharp increase in interest rates. [...] The other types of shocks are a sudden increase in uncertainty, a deterioration of corporate and household balance sheets, and weakened financial intermediaries. Some of these have clearly manifested themselves in the episode that has affected global financial markets in recent months.

Neste sentido, a teoria dominante trata as crises financeiras e as flutuações fortes do produto como anomalias e não como fenômenos intrínsecos ao processo de acumulação capitalista. As bolhas seriam falhas no comportamento racional dos agentes. Assim, Colander et al. (2008, p. 2) destacam a falha destes economistas em prever e lidar com a crise de forma adequada:

The majority of economists thus failed to warn policy makers about the threatening system crisis and ignored the work of those who did. Ironically, as the crisis has 
unfolded, economists have had no choice but to abandon their standard models and to produce hand-waving common-sense remedies.

Para compreender adequadamente a crise financeira, o primeiro passo é reconhecer que as crises desta natureza são recorrentes e não choques eventuais. A instabilidade financeira emerge como um resultado de mercado numa economia sofisticada financeiramente frente às incertezas com relação aos compromissos futuros (Minsky, 1982a).

A fragilidade financeira se desenvolve à medida que os participantes do mercado na busca por lucros promovem inovações financeiras que elevam a liquidez global da economia e criam endogenamente estruturas de financiamento cada vez mais vulneráveis (Minsky, 1982b). No caso específico desta crise, após a brutal queda das ações de alta tecnologia, as inovações no financiamento imobiliário permitiram a inflação de ativos com expansão dos investimentos e sustentação da renda agregada na economia americana ao mesmo tempo em que se garantia a estabilidade de preços. No entanto, o boom no financiamento promovido pelas inovações, num ambiente financeiro desregulado, promoveu uma forte alavancagem e aumentou o risco sistêmico ${ }^{9}$, ou seja, o risco de que a inadimplência ou mesmo a fragilização das unidades mais endividadas pudesse provocar uma fuga para segurança capaz de abalar os circuitos financeiros. Quando os sinais de esgotamento do processo começam a se manifestar, os mecanismos que garantiam as estruturas de financiamento se mostram insustentáveis $^{10}$. A crise tem início quando se detona o processo de queda dos preços de ativos para tentar honrar os compromissos e a iliquidez no sistema financeiro se revela.

Quando a bolha estoura e a crise de liquidez se instala, a Autoridade Monetária é chamada a restabelecer a estabilidade financeira com seu papel de lender of last resort, concedendo ou organizando empréstimos de liquidez. Para tanto, precisa agir discricionariamente, muitas vezes com a ajuda de outras instituições, como o Tesouro.

Mas será que é possível prevenir a formação da bolha? Cabe lembrar que os BCs foram criados com a função fundamental de garantir a estabilidade financeira. Para cumprir este papel, eles precisam de instrumentos para agir preventivamente, mesmo conscientes da continuidade das inovações financeiras e do sofisticado estágio de desenvolvimento do sistema bancário e financeiro. A dificuldade de estabelecer a regulação neste ambiente não significa abrir mão desta tarefa. Minsky (1988, p. 28), ao responder sobre os dilemas do Fed em

(9) O risco sistêmico "refere-se à possibilidade de que um choque localizado em algum ponto do sistema financeiro possa transmitir-se ao sistema todo e, eventualmente, levar a um colapso da própria economia." (Carvalho, 2005, p. 121).

(10) Para mais detalhes sobre o processo de inflação e deflação dos ativos americanos, ver Freitas e Cintra (2008). 
relação a questões regulatórias e às pressões do mercado por menos regulação, afirmou: "Rather than assuming a hands-off position on the oversight of activities, the Fed will have to increase its role in guiding financial behavior along lines that contribute to stability."

\section{Fed na formação da crise: antecedentes e a percepção sobre a bolha}

Não há consenso na literatura mainstream sobre qual deve ser a atuação do BC frente à formação de uma bolha de ativos. Deixando de lado as opiniões extremadas que negam a possibilidade de haver bolhas especulativas, identificamse duas correntes: uma advoga que o $\mathrm{BC}$ deve agir durante a formação da bolha, de modo a minimizar seus efeitos; outra defende que o BC deve agir apenas depois que a bolha estoura, conhecida como benign neglect.

Segundo Bordo e Jeanne (2002) e Tymoigne (2006), a visão dominante nos $\mathrm{BCs}$ é a benign neglect, para a qual a estabilidade de preços garante a estabilidade financeira. A suposição de mercados eficientes indica que é impossível para o BC saber, antes dos mercados, quando há uma bolha e, se o mercado sabe que há uma bolha, ele a corrigirá de imediato. Assim, o BC não deve se preocupar com os preços dos ativos, que são inerentemente voláteis.

Nesta linha, Bernanke e Gertler (2000) argumentam que o próprio sistema de metas de inflação faz com que o BC atue de fato sobre as bolhas, mesmo que esta ação não seja seu objetivo específico. Isto porque, na maioria das vezes, o crescimento dos preços dos ativos causa pressões inflacionárias devido ao efeito riqueza e à maior propensão à tomada de crédito, o que exigiria a elevação da taxa básica de juros. Além disso, a queda no preço dos ativos pode causar pressões deflacionárias, o que levaria à adoção de uma política monetária expansionista. No caso de estouro de uma bolha no preço de um ativo, a retração do sistema bancário teria efeitos deflacionários e a atuação de emprestador de última instância seria condizente com o sistema de metas de inflação ${ }^{11}$. A atuação do $\mathrm{BC}$ como emprestador de última instância se justificaria apenas nos raros episódios de crises.

Nessa linha, como apontam Blinder e Reis (2005), não é possível identificar a formação de uma bolha cedo o suficiente para que se faça algo a respeito sem cometer o erro (denominado de erro tipo II) de adotar medidas contra movimentos de preços que não são bolhas. Além disso, o BC não dispõe de instrumentos capazes de estourar uma bolha sem prejudicar seus outros objetivos. $\mathrm{O}$ BC controla somente a taxa de juros de curto prazo e a elevação requerida para desinflar uma bolha precisaria ser de tal magnitude que toda a economia seria afetada, com efeitos negativos desnecessários.

(11) Para Bernanke \& Gertler (2000, p. 3), as experiências históricas mostram que o colapso do preço de ativos prejudicou a economia real apenas quando a Autoridade Monetária não reagiu às pressões deflacionárias deflagradas pelo estouro da bolha e, mais ainda, quando reforçou tais pressões com medidas incorretas. 
A ação do Fed no período anterior à crise sugere o comportamento de benign neglect. Além de algumas atas do Federal Open Market Committee FOMC -, analisadas adiante, aponta, nesse sentido, a lentidão na elevação dos juros, iniciada apenas em 2004 (Gráficos 2 e 3) quando a alta dos imóveis já havia se descolado claramente dos preços ao consumidor (Gráfico 1). A liquidez folgada estimulou a concessão de créditos de maior risco, já estimulados por fatores poderosos, como a desregulamentação financeira e a classificação de risco pouco eficaz em relação aos ativos lastreados em hipotecas.

O excesso de liquidez está diretamente relacionado à política monetária expansiva mantida pelo Fed a partir de 2001, com a taxa básica de juros abaixo do observado nas décadas anteriores. Liquidez abundante e juros baixos impulsionaram a demanda por imóveis, com elevações sucessivas de preços desses ativos e novos estímulos à demanda pela expectativa de continuidade do processo de alta. O aumento acentuado no preço dos imóveis levou a redução da taxa de inadimplência e dos juros no mercado subprime, ocasionando uma classificação de risco mais favorável. Quando as taxas de juros de curto prazo subiram e voltaram aos níveis que eram usuais em períodos anteriores, a demanda por imóveis começou a declinar, o que foi reduzindo acentuadamente os preços e a contratação de novas construções. O resultado foi o aumento das taxas de default e a quebra no mercado subprime e de seus derivativos.

Cabe, então, discutir os motivos que levaram o Fed a manter a política monetária expansionista por tantos anos e a modificá-la de modo tão lento a partir de 2004. A forte queda dos juros em 2000-2001 está ligada à combinação entre o atentado de 11 de setembro de 2001, o estouro da bolha na Nasdaq e os escândalos corporativos. Tratava-se de proteger o sistema financeiro contra as pressões deflacionárias geradas pela combinação de problemas adversos dessa magnitude. Mais complexa é a análise dos motivos que determinaram a persistência nos juros baixos por tantos anos.

A análise de atas do FOMC (Federal Open Market Committee), principais meios de comunicação da Autoridade Monetária, mostra algumas justificativas para a manutenção dos juros baixos e também a avaliação que era feita sobre o comportamento do mercado imobiliário e o nível de consumo.

O Fed comunica em diversas ocasiões que a expansão do gasto no setor imobiliário e do consumo interno atenuava a tendência de desaceleração no nível de atividade da economia americana após 2001 (FED, 2002):

Concerning prospective developments in final demand in major sectors of the economy, several members underscored what they viewed as the key role of household expenditures. Such spending had held up remarkably well in the face of major adverse developments, including sharp declines in stock market wealth and rising unemployment that were exacerbated by the events of the September 11 (...) 
Residential construction expenditures, like household spending for consumer goods and services, had help up well despite the cyclical downturn in employment and sizeable net losses in stock market wealth. Low mortgage interest rates (...) had provided vital support to this sector of the economy.

Ainda:

The values of homes had continued to rise in most areas, and unusually low interest rates were inducing people to refinance mortgages and in the process to extract and spend some of the embedded equity gains. Increasing home equity values probably were providing some counterweight to the impact on consumer spending of the negative wealth effects associated with the declines in stock market prices since the spring of 2000 (Fed, 2002).

Além disso, o aumento da renda resultante da valorização dos ativos imobiliários e a consequente possibilidade de obtenção de crédito com lastro nos imóveis também impulsionavam o consumo. Conforme aponta trecho da ata do FOMC realizado em junho de 2002:

(...) With imbalances in inventories apparently largely worked off and the contribution of inventory investment to the expansion likely diminishing in coming quarters, final demand would play its usual primary role in determining the strength of the expansion. In that regard, consumer spending was seen as likely to provide some continuing (...), impetus to the growth of the economy. A favorable factor in this outlook cited by members was the ability and willingness of households to extract sizable financing resources for consumer and other expenditures by drawing on the appreciated equity in their homes in one form or another (...) (Fed, 2002, grifo nosso).

Durante os anos de 2002 a 2006 o consumo interno, impulsionado pelo setor imobiliário, foi constantemente citado pelos membros do FOMC como importante fator de sustentação da atividade econômica. Os primeiros sinais de preocupação quanto ao comportamento dos ativos imobiliários e os efeitos que os mesmos teriam sobre o consumo interno, no caso de uma reversão nos preços dos imóveis e aumento das taxas de financiamento, começam a surgir a partir de maio de 2004. O assunto foi abordado explicitamente em junho de 2005, assim como a discussão sobre qual reação a Autoridade Monetária deveria ter frente à formação de uma bolha no setor imobiliário. É o que se verifica na ata de junho de 2005 (Fed, 2005b):

At this meeting the Committee reviewed and discussed staff presentation on the topic of housing valuations and monetary policy. Prices of houses in the United States had risen sharply in recent years, especially in certain areas of the country, to very high levels relative to incomes or rents. In addition to local factors, a wide range of influences appeared to be supporting home prices, including solid gains in disposable income, low mortgage rates, and financial innovation in the residential mortgage market. Prices might be somewhat above the levels consistent with these 
underlying factors, but measuring the extent of any overvaluation either nationally or in regional markets posed considerable conceptual and statistical difficulties. Meeting participants noted that the rise in house prices had been accompanied by a modest shift toward potentially riskier types of mortgage, including adjustablerate and interest-only loans, which could pose challenges to both lenders and borrowers. Nonetheless, financial institutions generally remained in a comfortable capital position, such loans had performed well thus far, much of the associated risk had been transferred to other investors through securitization, and valuations had risen more rapidly than mortgage debt on average-so that loan to value ratios had fallen (Grifo nosso).

(...) meeting participants noted that the fundamentals underlying household spending remained firm. With rising home and equity prices buoying households' wealth, consumer expenditures continued to advance.

(...) Increased speculative activity in housing markets was evident in some parts of the country, but robust demand for new homes owed in large part to the ongoing economic expansion and low long-term mortgage rates.

As palavras a seguir confirmam a atuação do Fed segundo a visão dominante entre os bancos centrais de atuarem de acordo com benign neglect, uma vez que os preços dos ativos não contribuem para melhorar a previsão de inflação e produto.

(...) With regard to any role for monetary policy in responding to possible imbalances in housing or bond markets, meeting participants stressed the importance of the pursuit of their core objectives of price stability and maximum sustainable economic growth. To the extent that an asset price movement threatened the achievement of those objectives, it would of course be taken into consideration in setting policy. However, given the unavoidable uncertainties associated with judgments regarding the appropriate level of and likely future movements in asset prices, a strategy of responding more directly to possible mispricing was seen as very unlikely to contribute, on balance, to the achievement of the Committee's objectives over time (Fed, 2005b).

Esses trechos de atas do FOMC podem favorecer a interpretação de que o Fed aceitava os riscos no mercado imobiliário por preocupação com o nível de emprego. O problema teria origem, portanto, no duplo mandato (Taylor, 2009a). Como se sabe, diferentemente de outros bancos centrais que têm o objetivo único de manter a estabilidade de preços, o Fed deve buscar também o pleno emprego.

Há, no entanto, outra leitura possível: a preocupação principal do Fed era favorecer a recuperação dos mercados financeiros depois das crises de 2001-2002 e, em meio às tensões provocadas pela guerra do Iraque, preservar a desregulamentação e a ampla mobilidade de capitais, elementos básicos nas teses dominantes do Novo Consenso.

Nesse sentido, é importante destacar, nos Gráficos 2 e 3, que o corte na taxa de juros dos federal funds a partir do final de 2000 acompanha a queda 
acentuada na produção industrial e a elevação da taxa de desemprego. A alta dos juros em 2004, porém, começa quando o desemprego continua em níveis elevados para os padrões dos dez anos anteriores e coincide com a alta da inflação, embora discreta. A produção industrial voltou a mostrar crescimento mais firme apenas a partir do segundo semestre de 2004, depois da retomada da elevação dos juros, com a taxa de desemprego em 5,4\%. No período entre 2001 e 2005 , a taxa de inflação anual média variou entre 1,6\% em 2002 e 3,4\% em 2005.

Gráfico 1

Índice de Preço de Imóveis (compra) e Índice de Preço ao Consumidor (IPC)

$1^{\circ}$ trimestre de 1991 ao $2^{\circ}$ trimestre de 2009

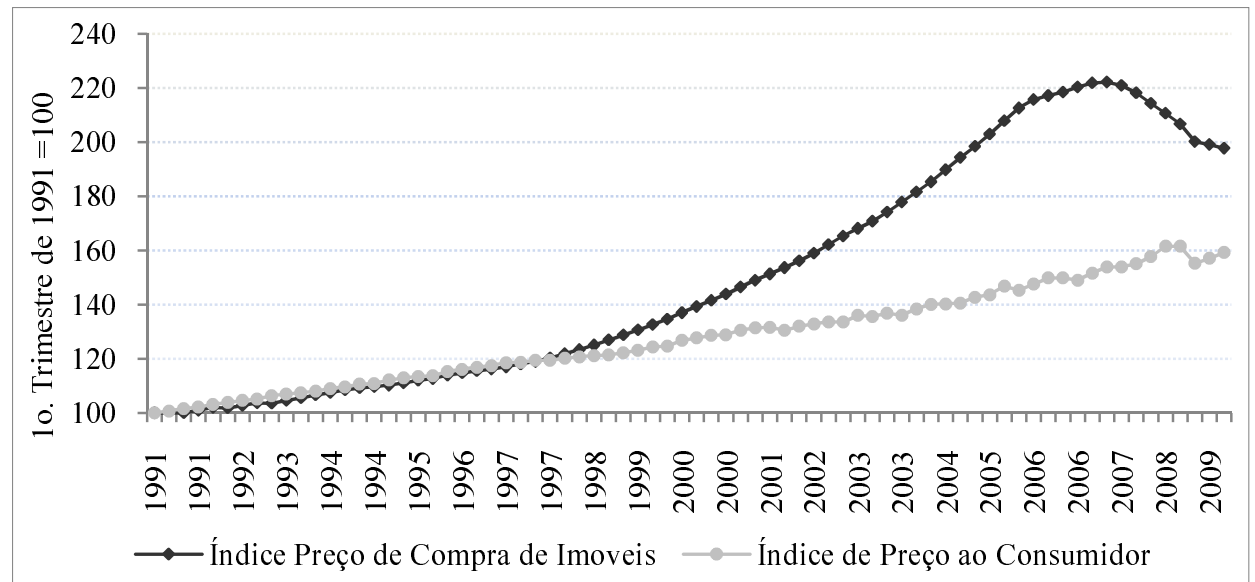

Fonte: Federal House Finance Agency.

Esses números sugerem que o Fed olhava mais para a volta da inflação do que para a defesa do emprego ou da produção industrial e era otimista com o quadro geral da economia e do sistema financeiro, apesar das fortes evidências de que o mercado imobiliário estava superaquecido. Segundo Wray (2004), o BC americano acreditava que a política monetária aplicada no período anterior era acomodatícia e que o Fed demonstrou os princípios do Novo Consenso que seguia quando aumentou os juros: transparência, gradualismo, ativismo, baixa inflação como objetivo principal e taxa de juros "neutra"12 como instrumento. O autor acredita que o ciclo de alta dos juros se iniciou cedo demais, quando o mercado de trabalho estava começando a se recuperar e quando não havia ainda pressões inflacionárias. Todavia, o Fed estava se mostrando "prisioneiro" das teses do Novo Consenso, principalmente no que se refere a atender as expectativas de mercado para não minar sua credibilidade.

(12) A taxa neutra de juros é aquela que não causa nem inflação, nem desemprego. O próprio Fed afirma que não sabe qual realmente é o seu valor e que somente o saberá ex-post (Wray, 2004). 
Gráfico 2

Taxa de desemprego e taxa de juros dos Federal Funds (efetiva) janeiro de 1991 a fevereiro de 2009

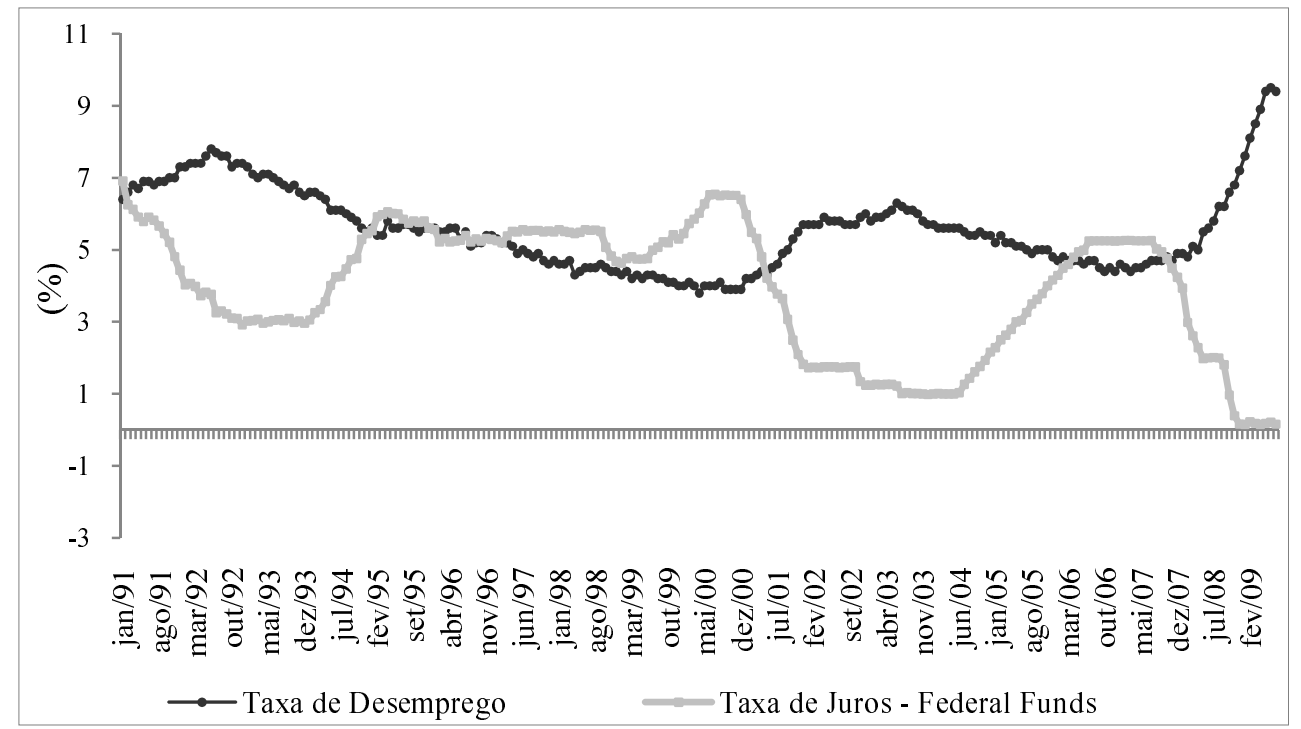

Fonte: Bureau of Labor Statistics e Federal Reserve.

Gráfico 3

Taxa de inflação (Consumer Price Index) e Taxa de juros dos Federal Funds (efetiva) - janeiro de 1991 a fevereiro de 2009

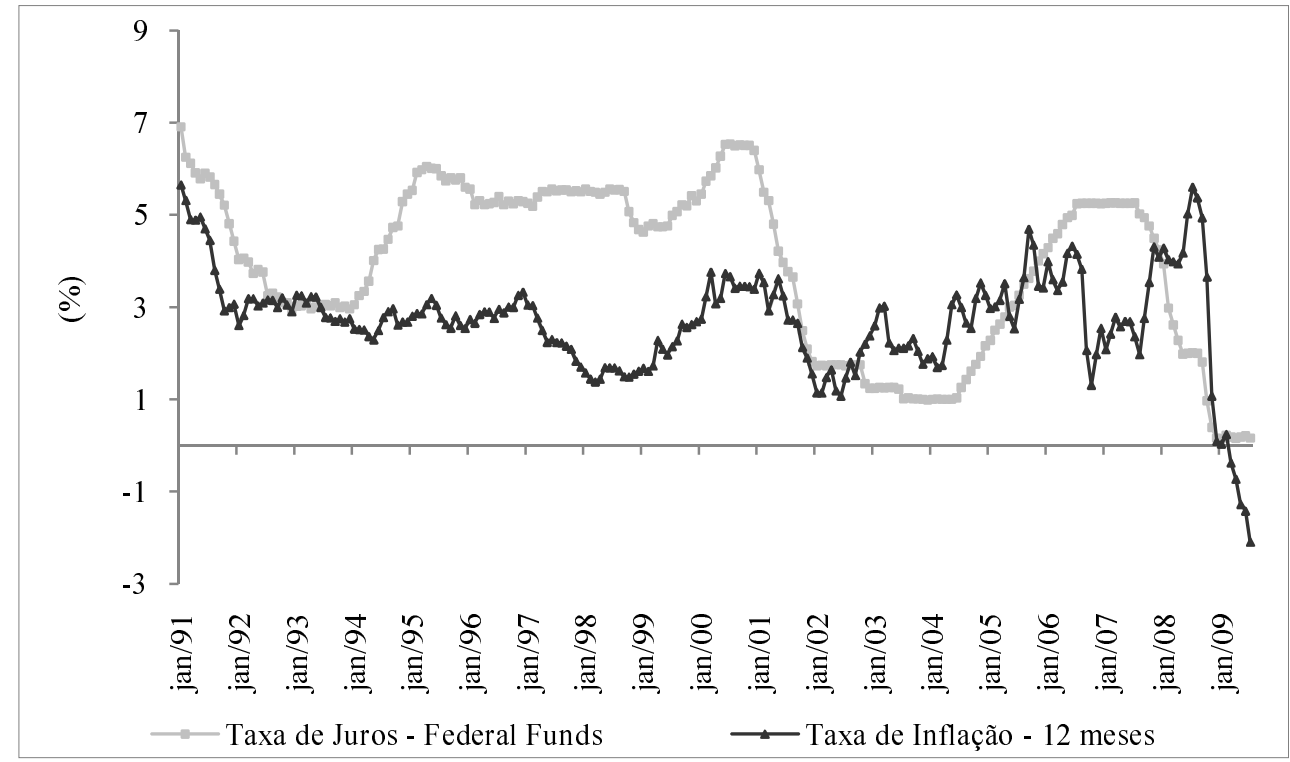

Fonte: Bureau of Labor Statistics e Federal Reserve.

Economia e Sociedade, Campinas, v. 20, n. 2 (42), p. 329-364, ago. 2011. 


\section{O Fed na crise: dos instrumentos tradicionais à ação discricionária}

Esta seção analisa a atuação do Fed a partir de agosto de 2007, quando os instrumentos tradicionais de política monetária foram acionados para conter a crise (Quadro 1). Como esses instrumentos se mostraram insuficientes, a partir de dezembro de 2007, o Fed passou a criar instrumentos monetários discricionários para tentar estabilizar o sistema fragilizado, processo que se estendeu ao longo de 2008 e início de 2009 (Quadro 2). Até setembro de 2008, os novos instrumentos foram acomodados no balanço do Fed com alterações nos saldos de diferentes contas. Naquele mês, em resposta ao agravamento da crise, o balanço do Fed passou a crescer de forma acelerada, de US\$ 900 bilhões em média, nos meses anteriores, para US\$2,293 trilhões no final de dezembro de 2008, patamar em que se manteve até setembro de 2009 (Tabela 1).

A partir de setembro de 2008, o aumento do balanço do Fed passou a ser o principal instrumento de política monetária e o manejo das novas contas permitiu ao $\mathrm{BC}$ afetar a quantidade e o preço dos fundos disponíveis para o sistema financeiro (Cecchetti, 2008a). O paradigma do Novo Consenso dava ao BC somente o open market como instrumento para garantir a liquidez do mercado interbancário e isso foi colocado em questionamento durante a crise (Chailloux et al., 2008).

A primeira subseção resume o uso dos instrumentos tradicionais de política monetária pelo Fed e a criação de novos instrumentos, e as iniciativas discricionárias adotadas a partir de dezembro de 2007. As duas subseções seguintes discutem a natureza desses novos instrumentos e iniciativas bem como seus efeitos sobre o ativo e sobre o passivo do Fed. Para isso, analisa-se o balance sheet do Fed em datas selecionadas a fim de observar o impacto das novas contas. Como se verifica na Tabela 1, grande parte desses novos instrumentos foram criados a partir de setembro de 2008 quando os impactos da quebra do banco Lehman Brothers colocaram o risco agudo de iliquidez do sistema interbancário.

Fica evidente que o Fed foi muito além da função tradicional de emprestador de última instância para bancos em dificuldades e passou a atuar e interferir de forma discricionária em diversos mercados de formas pouco usuais. A vigorosa expansão do balance sheet do Fed destinou-se, de início, a conceder empréstimos e melhorar a liquidez dos mercados e, depois, à aquisição de títulos do Tesouro e das agências Fannie Mae, Freddie Mac e Ginnie Mae. Essa expansão foi possível, em grande parte, devido ao aumento vertiginoso da conta de reservas bancárias.

A concepção tradicional de um $\mathrm{BC}$ que opera via open market, comprando e vendendo títulos ao preço de mercado e visando manter a taxa de juros de curto prazo estável, já não mais se aplica ao Fed. O que se vê hoje não é uma 
Autoridade Monetária que deixa a decisão de como alocar os fundos ao mercado. O Fed está atuando endogenamente em setores que julga serem prioritários, sejam bancos ou não. Taylor (2009b) chega a afirmar que o Fed está fazendo uma mistura de política monetária com política industrial.

\subsection{Instrumentos tradicionais e discricionariedade na ação do Fed}

Até agosto de 2007, o Fed fazia política monetária com os instrumentos tradicionais: operações de mercado aberto, empréstimos de redesconto e requerimentos de reserva.

As operações de open market procuram manter a taxa dos federal funds na meta estipulada pelo FOMC. Essa é a taxa básica utilizada pelos bancos nos empréstimos interbancários overnight. Esse instrumento atinge a economia diretamente pelos canais de transmissão - câmbio, crédito e ativos. A mesa de operações do Federal Reserve de Nova York ${ }^{13}$ faz operações overnight de compra e venda de títulos com os primary dealers, um conjunto de 19 bancos de investimento. Em setembro de 2007, o Fed começou a cortar progressivamente a meta de taxa de juros dos títulos federais até reduzi-la para a banda de $0 \%$ a $0,25 \%$ na última reunião de 2008 (Gráfico 4).

Gráfico 4

Mudanças na Federal Funds Target Rate setembro de 2007 a dezembro de 2008 (em \%)

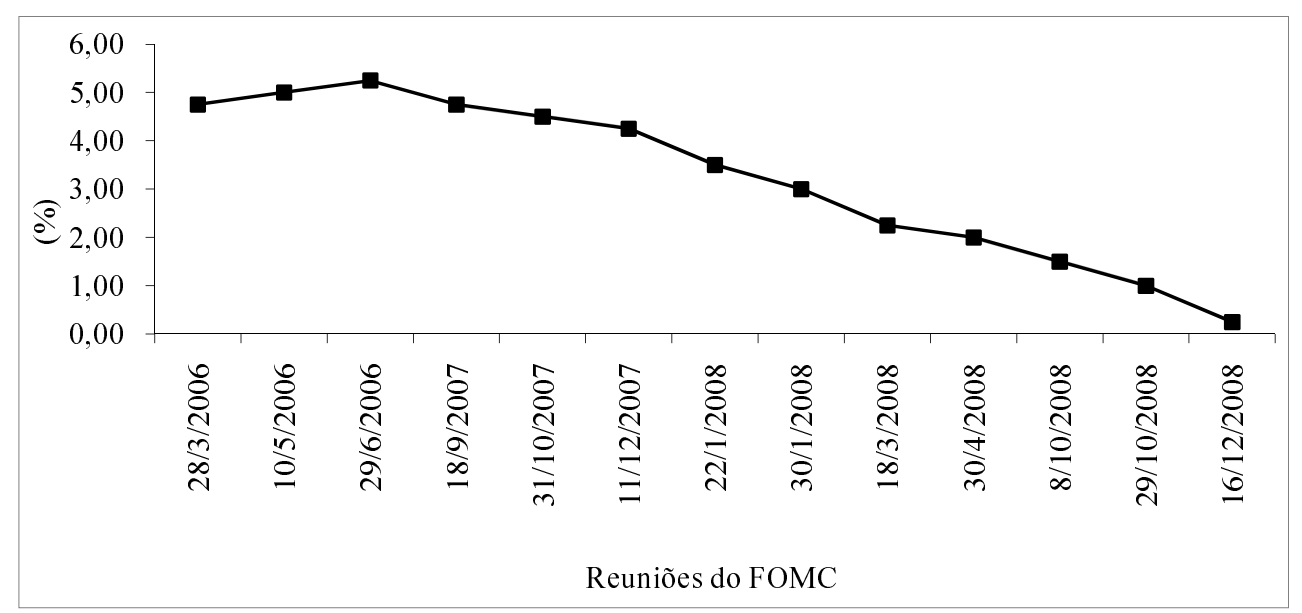

Fonte: Federal Reserve Board.

(13) O Federal Reserve System (Fed) é composto por uma agência governamental central - Board of Governors - e 12 bancos centrais regionais - Regional Federal Reserve Banks. Os bancos centrais regionais são os braços operacionais do sistema bancário central. A agência central é responsável pela supervisão das operações e atividades dos bancos regionais. 
O segundo instrumento tradicional de política monetária é a taxa de redesconto, que é um empréstimo colateralizado acessível apenas a bancos comerciais, visto, tradicionalmente, como um instrumento de auxílio para aliviar pressões de liquidez do mercado. As taxas cobradas, primary e secondary credit, foram mantidas sempre entre 50 e 100 pontos básicos acima da meta da taxa de juros dos federal funds, respectivamente. Durante a crise, para estimular a tomada de crédito pelos bancos, a taxa primary credit, disponível para empréstimos overnight para instituições bancárias saudáveis, caiu de 5,75\% ao ano em agosto de 2007 para $0,5 \%$ ao ano em dezembro de 2008 apenas 25 pontos básicos acima da taxa dos títulos federais. A taxa secondary credit, disponível para instituições que não podem acessar a linha de primary credit, ficou 50 pontos básicos acima da taxa de primary credit. O redesconto sofreu também alterações de prazo com o alongamento do primary credit para 30 dias em agosto de 2007 e para 90 dias em março de 2008. As taxas de primary credit e secondary credit permanecem inalteradas até setembro de 2009, desde sua última redução (Gráfico 5).

Gráfico 5

Taxas de redesconto - Primary Credit e Secondary Credit agosto de 2007 a dezembro de 2008 (em \%)

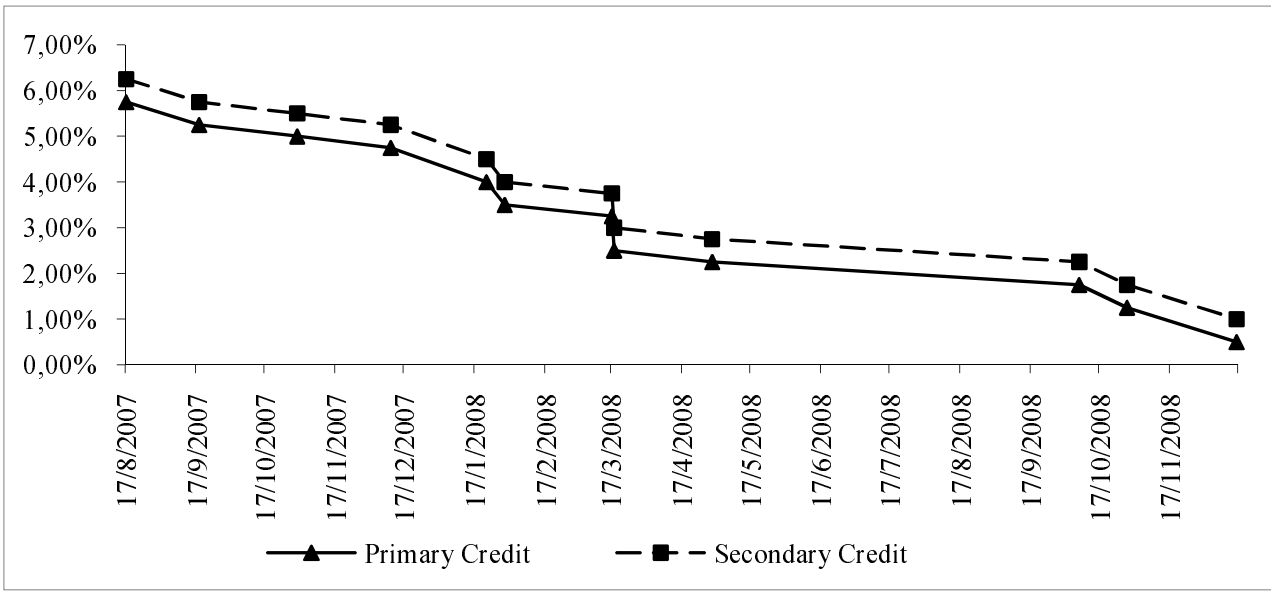

Fonte: Federal Reserve Bank Discount Window \& Payment System Risk.

O terceiro instrumento são os três tipos de reservas bancárias: reservas requeridas ou compulsórias; reservas de clearing, para facilitar as compensações diárias e reservas excedentes (FED, 2005a). Em outubro de 2008 o Fed determinou que as reservas compulsórias e excedentes passassem a render juros, medida que será discutida adiante, na análise do passivo do Fed.

Muito antes disso, porém, em dezembro de 2007, o Fed deu início à criação de diversos programas de assistência financeira e de compra de ativos (Quadro 2) ao mesmo tempo que acentuou o corte das taxas de juros (Gráfico 4). As iniciativas discricionárias e a criação de novos instrumentos de atuação 
indicam que o Fed concluiu que as ferramentas tradicionais de política monetária não seriam suficientes para estabilizar o mercado.

Quadro 1

Principais ações do Fed com instrumentos tradicionais agosto/2007-dezembro/2008

\begin{tabular}{|c|c|}
\hline \multicolumn{2}{|r|}{ Instrumentos tradicionais } \\
\hline Data & Ação \\
\hline 9 de agosto de 2007 & Aumento do volume de operações com open market \\
\hline 17 de agosto de 2007 & $\begin{array}{l}\text { Corte da taxa primária de redesconto de } 100 \text { para } 50 \text { pontos básicos } \\
\text { acima da meta de taxa de juros; aumentou o prazo do empréstimo de } \\
\text { redesconto de } 1 \text { dia para } 30 \text { dias }\end{array}$ \\
\hline 18 de setembro de 2007 & $\begin{array}{l}\text { Corte da taxa de juros em } 50 \text { pontos básicos em reunião regular do } \\
\text { FOMC, de } 5,25 \% \text { a.a para } 4,75 \% \text { a.a }\end{array}$ \\
\hline 31 de outubro de 2007 & $\begin{array}{l}\text { Corte da taxa de juros em } 25 \text { pontos básicos em reunião regular do } \\
\text { FOMC, de } 4,75 \% \text { a.a para } 4,50 \% \text { a.a }\end{array}$ \\
\hline 11 de dezembro de 2007 & $\begin{array}{l}\text { Corte da taxa de juros em } 25 \text { pontos básicos em reunião regular do } \\
\text { FOMC, de } 4,50 \% \text { a.a para } 4,25 \% \text { a.a }\end{array}$ \\
\hline 21 de janeiro de 2008 & $\begin{array}{l}\text { Corte da taxa de juros em } 75 \text { pontos básicos em reunião não programada } \\
\text { do FOMC (maior corte em } 25 \text { anos), de } 4,25 \% \text { a.a para } 3,50 \% \text { a.a }\end{array}$ \\
\hline 30 de janeiro de 2008 & $\begin{array}{l}\text { Corte da taxa de juros em } 50 \text { pontos básicos em reunião regular do } \\
\text { FOMC, de } 3,50 \% \text { a.a para } 3,00 \% \text { a.a }\end{array}$ \\
\hline 16 de março de 2008 & $\begin{array}{l}\text { Corte da taxa primária de redesconto de } 50 \text { para } 25 \text { pontos básicos acima } \\
\text { da meta de taxa de juros; aumento do prazo máximo dos empréstimos } \\
\text { de redesconto de } 30 \text { para } 90 \text { dias }\end{array}$ \\
\hline 18 de março de 2008 & $\begin{array}{l}\text { Corte da taxa de juros em } 75 \text { pontos básicos em reunião regular do } \\
\text { FOMC, de } 3,00 \% \text { a.a para } 2,25 \% \text { a.a }\end{array}$ \\
\hline 30 de abril de 2008 & $\begin{array}{l}\text { Corte da taxa de juros em } 25 \text { pontos básicos em reunião regular do } \\
\text { FOMC, de } 2,25 \% \text { a.a para } 2,00 \% \text { a.a }\end{array}$ \\
\hline 6 de outubro de 2008 & $\begin{array}{l}\text { Anúncio do início de pagamento de juros nas reservas bancárias } \\
\text { compulsórias e em excesso }\end{array}$ \\
\hline 8 de outubro de 2008 & $\begin{array}{l}\text { Corte da taxa de juros em } 50 \text { pontos básicos em reunião regular do } \\
\text { FOMC, de } 2,00 \% \text { a.a para } 1,50 \% \text { a.a }\end{array}$ \\
\hline 29 de outubro de 2008 & $\begin{array}{l}\text { Corte da taxa de juros em } 50 \text { pontos básicos em reunião regular do } \\
\text { FOMC, de } 1,50 \% \text { a.a para } 1,00 \% \text { a.a }\end{array}$ \\
\hline 16 de dezembro de 2008 & $\begin{array}{l}\text { Corte na taxa de juros em } 75 \text { pontos básicos em reunião regular do } \\
\text { FOMC, de } 1,00 \% \text { a.a para uma banda de } 0,25 \% \text { - } 0 \% \text { a.a }\end{array}$ \\
\hline
\end{tabular}

Fonte: Cecchetti (2009); Crotty e Epstein (2008) e Fed (2008).

As duas subseções a seguir discutem essas iniciativas e os novos instrumentos e analisam seu impacto sobre o ativo e sobre o passivo do Fed. A partir de setembro de 2008, conforme comentado, o balanço do banco central norte-americano mudou drasticamente sua composição e tamanho. Antes da crise, o tamanho do balance sheet do Fed era aproximadamente US\$ 870 bilhões, saltando para mais de US\$ 2 trilhões em setembro de 2008. Os itens tradicionais 
do balanço - títulos e operações de open market conhecidos também como "repos") caíram aproximadamente US\$ 224,5 bilhões até dezembro de 2008 (Gavin, 2009).

Quadro 2

Iniciativas discricionárias e criação de instrumentos discricionários pelo Fed dezembro/2007 - janeiro/2009

\begin{tabular}{|c|c|}
\hline Data & Ação \\
\hline 12 de dezembro de 2007 & $\begin{array}{l}\text { Criação do Term Auction Facility (TAF) e linhas de swap com o } \\
\text { European Central Bank (ECB) e o Banco Central da Suíça de US\$ } 20 \\
\text { bilhões e US\$ } 4 \text { bilhões, respectivamente }\end{array}$ \\
\hline zembr & Primeira operação de TAF: US\$ 20 bilhões, 98 operadores \\
\hline 2 de março de 2008 & $\begin{array}{l}\text { Anúncio de intenção de realizar operações de recompra de } 28 \text { dias, em } \\
\text { um total de US\$ } 100 \text { bilhões }\end{array}$ \\
\hline 7 de março de 2008 & $\begin{array}{l}\text { Aumento nas operações de TAF de US\$ } 60 \text { bilhões para US\$ } 100 \\
\text { bilhões }\end{array}$ \\
\hline 11 de março de 2008 & $\begin{array}{l}\text { Criação do Term Securities Lending Facility (TSLF) e a intenção de } \\
\text { emprestar US\$ } 200 \text { bilhões em títulos do Tesouro para os Primary } \\
\text { Dealers. Aumentou a linha de swap com EBC e o Banco Central da } \\
\text { Suíça para US\$ } 30 \text { bilhões e US\$ } 6 \text { bilhões, respectivamente }\end{array}$ \\
\hline 14 de março de 2008 & $\begin{array}{l}\text { Fed anunciou a aprovação do empréstimo ao Bear Sterns junto ao JP } \\
\text { Morgan Chase }\end{array}$ \\
\hline $16 \mathrm{~d}$ & $\begin{array}{l}\text { Criação do Primary Dealer Credit Facility (PDCF); aprovação de } \\
\text { empréstimo de US\$ } 30 \text { bilhões para o JP Morgan Chase adquirir o } \\
\text { Bear Sterns }\end{array}$ \\
\hline 2 de & $\begin{array}{l}\text { Aumento das operações de TAF para US\$ } 150 \text { bilhões. Aumento das } \\
\text { linhas de swap com os ECB e o Banco Central da Suíça para US\$ } 50 \\
\text { bilhões e US\$ } 12 \text { bilhões, respectivamente; expansão do colateral } \\
\text { exigido para o TSLF para incluir securities avaliadas como AAA }\end{array}$ \\
\hline 7 de setembro de 2008 & $\begin{array}{l}\text { Tesouro americano nacionaliza Fannie Mae e Freddie Mac, prometendo } \\
\text { US\$ } 100 \text { bilhões para cada }\end{array}$ \\
\hline tembro d & $\begin{array}{l}\text { Falência do Lehman Brothers. Fed diz que não irá socorrer Lehman } \\
\text { Brothers e AIG. }\end{array}$ \\
\hline 16 de setembro de 2008 & $\begin{array}{l}\text { Socorro da AIG pelo Fed, com empréstimo de US\$ } 85 \text { bilhões, tomando } \\
79,9 \% \text { das ações. }\end{array}$ \\
\hline tembro c & $\begin{array}{l}\text { nentary Financing Program" pelo Tesouro, para deixar } \\
\text { s disponíveis ao Fed }\end{array}$ \\
\hline $18 \mathrm{de}$ & $\begin{array}{l}\text { Proposto programa de bail-out de US\$ } 700 \text { bilhões pelo Tesouro; Fed e } \\
\text { Bancos Centrais da Europa injetam bilhões de dólares em operação } \\
\text { coordenada de liquidez; Fed cria nova ferramenta de liquidez para } \\
\text { comprar Commercial Papers. }\end{array}$ \\
\hline 19 de se & $\begin{array}{l}\text { Criação do Asset Backed Commercial Paper (ABCP) Money Market } \\
\text { Mutual Funds (MMMF) Liquidity Facility (AMLF) }\end{array}$ \\
\hline $7 \mathrm{de}$ & Criação do Commercial Paper F \\
\hline 21 de outubro de 2008 & et Investor Funding Facility (MMIFF) \\
\hline 25 de novembro de 2008 & acked Securities Loan Facility (TALF) \\
\hline 15 de jan & $\begin{array}{l}\text { Início da compra de Mortgage Backed Securities (MBS), garantidas por } \\
\text { Fannie Mae, Freddie Mac e Ginnie Mae }\end{array}$ \\
\hline
\end{tabular}

Fonte: Cecchetti (2009); Crotty e Epstein (2008) e Fed (2008). 


\subsection{Mudanças no balanço do Fed: análise das contas do ativo}

$\mathrm{O}$ ativo do Fed é dado pela tabela "Fatores ofertando reservas para os bancos depositários" e o passivo é dado pelos "Fatores absorvendo reservas dos bancos depositários". Os valores apresentados nas Tabelas 1 e 2, abaixo, correspondem à média diária do dia antes da publicação ${ }^{14}$ e são compostos pela agregação dos balanços dos doze Federal Reserve Banks regionais.

A Tabela 1, a seguir, mostra o ativo do balanço do Fed. As contas (1) US Treasury, (2) Federal Agency debt securities e (3) Mortgage-backed securities referem-se ao total de títulos em poder do Fed. Podemos verificar que, em julho de 2007, os US Treasuries, que são títulos do Tesouro Americano, correspondiam a quase $87 \%$ do total do balanço. Em 29 de dezembro de 2008, essa porcentagem era de apenas $21 \%$. Isso mostra a mudança do balanço do Fed tanto em tamanho quanto em composição. Até setembro de 2008, as linhas de crédito criadas pelo Fed foram financiadas por venda de títulos. Ou seja, até essa data, houve somente recomposição das contas do ativo. Após setembro de 2008, o financiamento dessas linhas foi feito via aumento do total do passivo, conforme se analisará mais a frente (Gavin, 2009).

A conta (2) refere-se a títulos de agências governamentais, como Fannie Mae e Freddie Mac. O Fed não os adquiria antes da crise e vemos que, a partir de setembro de 2008, eles passam a compor o ativo. A conta (3) criada em 15 de janeiro de 2009 indica os valores referentes à compra de mortgage-backed securities (MBS), garantidas pelas agências Fannie Mae, Freddie Mac e Ginnie $\mathrm{Mae}^{15}$. Este programa tem como objetivo melhorar as condições gerais dos mercados financeiros e diminuir as taxas cobradas nas hipotecas (Fed, 2009). Em 18 de março, o FOMC anunciou que compraria um total de US\$1,25 trilhão em MBS, US\$ 200 bilhões em títulos das agências governamentais até o final de 2009 e US\$ 300 bilhões em US Treasuries até outubro de $2009^{16}$. Pela análise das contas (1), (2) e (3), entre março e setembro de 2009, o Fed já adquiriu aproximadamente US\$290 bilhões em US Treasuries, US\$ 79 bilhões em títulos das agências e US\$ 694 bilhões em MBS. Assim, o total de títulos em poder do Fed ("Securities held outright") passou de US\$ 790 bilhões em julho de 2007 (inteiramente composto por US Treasuries) para US\$ 1,5 trilhão em setembro de 2009, dos quais 43\% são MBS adquiridas das agências.

(14) Exceto pelo dia 29 de dezembro de 2008, cujos valores são referentes ao dia 24 de dezembro de 2008.

(15) Fannie Mae, Freddie Mac e Ginnie Mae são GSE - government-sponsored enterprises. São empresas privadas, mas garantidas pelo governo. Seu papel é formar um mercado secundário para as hipotecas, comprando-as diretamente dos emprestadores, securitizando-as ou mantendo-as em suas carteiras. O Fed está adquirindo os títulos emitidos por estas agências.

(16) Essas operaç̃es são realizadas pela mesa de mercado aberto do Federal Reserve Bank of New York, chamada de SOMA - System Open Market Account.

Economia e Sociedade, Campinas, v. 20, n. 2 (42), p. 329-364, ago. 2011. 
A conta (4) indica o total dos acordos de recompra (operações "temporárias"), ou seja, é o instrumento de open market, já discutido anteriormente. Apesar do seu valor ter mais que dobrado no período analisado, vêse que houve queda das operações no total do ativo. Seu volume é pequeno quando comparado aos novos instrumentos criados, como o Term Auction Facility (TAF), cujos valores estão na linha (5). Em 29 de dezembro de 2008, 20\% do total do ativo do Fed era composto pelo TAF, enquanto somente 3,5\% era de operações de mercado aberto. A partir de março de 2009, não há mais operações de repos feitas pelo Fed, uma vez que as compras de títulos estão sendo feitas via operações definitivas com títulos incorporados ao balanço (linhas (1), (2) e (3), explicadas acima).

O TAF, criado pelo Fed em 12 de dezembro de 2007, tem como objetivo facilitar a tomada de empréstimos pelos bancos comerciais, já que a política de redução da taxa de redesconto não estava tendo o efeito esperado. A principal dificuldade apontada na tomada de empréstimos via redesconto é o problema do "estigma". O Fed sempre desencorajou a tomada desses empréstimos, seguindo a concepção de Bagehot e aplicando taxas punitivas. Se um banco acessasse a linha de redesconto, isto era visto como sinal de fraqueza, uma vez que se supõe que ele foi primeiramente ao mercado e não encontrou agentes dispostos a emprestar-lhe os fundos.

Através do TAF, o Fed empresta volumosas quantidades de reservas por um período mais longo, 28 ou 35 dias inicialmente, chegando a 84 dias em julho de 2008 (Chailloux et al., 2008). O espectro de títulos que podem ser usados como colateral também aumentou. Todos os bancos comerciais nos Estados Unidos que têm acesso ao primary credit podem participar do leilão e o "lance" não pode ultrapassar $50 \%$ do valor do colateral que o banco tem disponível para empréstimos de redesconto. Há garantia de anonimato para os bancos, o que pretende resolver o problema de "estigma". O resultado esperado do TAF era de que a liquidez pudesse, assim, chegar aos bancos menores (Cecchetti, 2009). Em 25 de junho de 2009, o FOMC divulgou através do site do Fed que a economia estava se recuperando e que os lances no TAF estavam sendo menores do que a oferta pelo Banco Central. Assim, esse instrumento vem perdendo importância, mas continua em operação, sem previsão de término pelo Fed.

Nas linhas (6) e (7), primary credit e secondary credit, há o total de empréstimos de redesconto. Em julho de 2007, o valor dessa conta era praticamente inexistente, de US\$ 5 milhões. Esse montante também foi se elevando com o agravamento da crise, chegando a US\$ 91 bilhões em novembro de 2008. 
Tabela 1

Balance Sheet do Federal Reserve (Ativo) (em milhões de dólares)

\begin{tabular}{|c|c|c|c|c|c|c|c|c|}
\hline & $5 / 7 / 07$ & $4 / 10 / 07$ & $3 / 4 / 08$ & $25 / 9 / 08$ & $28 / 11 / 08$ & $29 / 12 / 08$ & $26 / 3 / 09$ & $24 / 9 / 09$ \\
\hline Reserve Bank Credit & 860.319 & 854.970 & 867.695 & 1.196 .804 & 2.091 .608 & 2.241 .288 & 2.055 .282 & 2.141 .055 \\
\hline US Treasury (1) & 790.553 & 779.624 & 581.240 & 476.578 & 476.407 & 476.014 & 474.746 & 765.633 \\
\hline Mortgage-backed securities (3) & N/A & N/A & N/A & N/A & N/A & $\mathrm{N} / \mathrm{A}$ & 236.156 & 693.595 \\
\hline Repurchase Agreements (4) & 30.250 & 35.250 & 76.000 & 86.000 & 80.000 & 80.000 & 0 & 0 \\
\hline Term Auction Credit - TAF (5) & N/A & N/A & 100.000 & 150.000 & 406.508 & 450.219 & 468.589 & 196.020 \\
\hline Secondary Credit (7) & 0 & 0 & 0 & 19 & 186 & 40 & 1 & 583 \\
\hline Seasonal Credit & 181 & 153 & 12 & 101 & 6 & 3 & 4 & 125 \\
\hline Primary Dealer and other broker-dealer credit - PDCF (8) & N/A & N/A & 34.443 & 105.662 & 57.886 & 38.190 & 20.175 & 0 \\
\hline $\begin{array}{l}\text { Asset-Backed commercial paper money market mutual } \\
\text { fund liquidity facilility - AMLF (9) }\end{array}$ & N/A & N/A & N/A & 72.667 & 53.309 & 23.993 & 6.845 & 79 \\
\hline Credit extended to AIG (10) & N/A & N/A & $\mathrm{N} / \mathrm{A}$ & N/A & 55.936 & 39.507 & 43.188 & 38.810 \\
\hline $\begin{array}{l}\text { Net portfolio holdings of LLCs funded through the money } \\
\text { market investor funding facility - MMIFF (13) }\end{array}$ & N/A & N/A & $\mathrm{N} / \mathrm{A}$ & N/A & 0 & 0 & 0 & 0 \\
\hline Net portfolio holdings of Maiden Lane LLC (14) & N/A & N/A & N/A & 29.407 & 26.979 & 26.966 & 26.288 & 26.189 \\
\hline Net portfolio holdings of Maiden Lane II LLC (15) & N/A & N/A & $\mathrm{N} / \mathrm{A}$ & N/A & $\mathrm{N} / \mathrm{A}$ & 20.049 & 18.449 & 14.662 \\
\hline Net portfolio holdings of Maiden Lane III LLC (16) & N/A & N/A & N/A & N/A & 21.148 & 28.191 & 27.645 & 20.554 \\
\hline Float & -906 & -658 & 1.473 & -1.412 & -1.514 & -1.334 & -2.393 & -1.916 \\
\hline Central Bank Liquidity Swaps (17) & N/A & N/A & $\mathrm{N} / \mathrm{A}$ & N/A & N/A & N/A & 327.778 & 59.121 \\
\hline Other Federal Reserve assets (18) & 40.237 & 40.574 & 64.185 & 183.890 & 516.717 & 621.990 & 50.092 & 85.571 \\
\hline Gold Stock & 11.041 & 11.041 & 11.041 & 11.041 & 11.041 & 11.041 & 11.041 & 11.041 \\
\hline Special drawing rights certificate account & 2.200 & 2.200 & 2.200 & 2.200 & 2.200 & 2.200 & 2.200 & 5.200 \\
\hline Treasury currency outstanding & 38.540 & 38.651 & 38.736 & 38.774 & 38.787 & 38.843 & 38.842 & 42.579 \\
\hline Total factors supplying reserve funds (19) & 912.101 & 906.861 & 919.671 & 1.248 .819 & 2.143 .636 & 2.293 .372 & 2.107 .365 & 2.199 .875 \\
\hline
\end{tabular}

Fonte: Federal Reserve Statistical Release H.4.1, várias datas. Obs. N/A significa que a conta não existia na data. 
Como os bancos de investimento não têm acesso ao primary credit e nem ao TAF, em 16 de março de 2008, o Fed criou o Primary Dealer Credit Facility (PDCF), que se encontra na linha (8). Essa ferramenta autoriza os primary dealers a acessar a janela de redesconto, com empréstimos overnight e com colaterais variados ${ }^{17}$ (Fed, 2008). De acordo com Cecchetti (2008a), o PDCF tinha dois objetivos: direcionar liquidez aos bancos de investimento e diminuir o spread no mercado dos colaterais que são aceitos. O Fed, ao criar esse instrumento, percebeu que a função de prestamista de última instância precisava ser estendida a outras instituições, além das depositárias. O PDCF atingiu seu pico em setembro de 2008, chegando a US\$ 105 bilhões. Apesar de seu valor ter caído para zero em setembro de 2009, o Fed decidiu manter o programa até, pelo menos, $01 \mathrm{de}$ fevereiro de 2010 (Fed, 2009).

A linha (9) mostra o programa criado em 19 de setembro de 2008, o AssetBacked Commercial Paper (ABCP), Money Market Mutual Fund (MMMF), Liquidity Facility (AMLF). O Fed percebeu que os fundos mútuos não estavam conseguindo vender seus ativos, uma vez que os mercados estavam ilíquidos. Um desses mercados é o de commercial papers (CP) lastreados em ativos. Assim, o programa visa restaurar a liquidez neste mercado, emprestando dinheiro à taxa de primary credit diretamente para os investidores para comprar $\mathrm{ABCP}$ de alta qualidade de fundos mútuos. Este mercado sofreu com a queda do Lehman Brothers, uma vez que US\$ 133 bilhões foram retirados do money market nos dois dias seguintes à falência do banco ${ }^{18}$. O montante das operações do AMLF teve seu pico em setembro, quando atingiu quase US\$ 73 bilhões. Entretanto, o mercado de ABCP permaneceu travado, com os juros de 30 dias para títulos com rating AA subindo de 2,7\% em 8 de agosto de 2008 para 5,5\% no início de outubro de 2008 (Labonte, 2008).

Devido a isto, o Fed cria, em 7 de outubro de 2008, o Commercial Paper Funding Facility (CPFF), que se encontra na linha (12) do ativo. Para este instrumento, foi estabelecida uma Limited Liability Company (LLC), que é um Special Purpose Vehicle (SPV) instituído para emprestar dinheiro do Fed com o intuito de comprar qualquer tipo de commercial paper de 3 meses de alta qualidade. Segundo Labonte (2008), esse é o primeiro instrumento em 70 anos desenvolvido para comprar ativos, ao invés de emprestar dinheiro a instituições. Apesar de ter sido criada uma empresa para essa compra, quem está por detrás das operações é realmente o Fed, que contabilizará as perdas, caso ocorram. O

(17) Os colaterais aceitos são todos os títulos consentidos nas operações de open market, mais títulos de empresas com investment grade, títulos municipais, títulos "mortgage-backed" e títulos "asset-backed" (Fed, 2008).

(18) http://macroblog.typepad.com/macroblog/2008/10/mmmf-and-amlf-a.html. 
objetivo desse programa é fazer os investidores privados voltarem a comprar commercial papers. Nota-se que, aqui, os CPs não são mais lastreados em ativos, e o Fed está comprando ativos que não são colateralizados. A conta criada mostra o valor dos ativos da LLC, que, em dezembro de 2008, atingiu US\$ 331 bilhões de dólares.

Além desses programas, foi instituído, em 24 de novembro de 2008, o Money Market Investor Funding Facility (MMIFF) - linha (13) - para o qual não observamos movimentação até o final de nossa análise em setembro de 2009. Foi criada uma série de LLCs, que irá prover fundos para o setor privado para financiar a compra de ativos de curto prazo, como notas bancárias, certificados de depósito e commercial papers, por investidores e fundos mútuos. O objetivo é aumentar a liquidez, facilitando a venda de ativos e aumentando a disponibilidade de crédito. O MMIFF visa complementar o CPFF (Fed, 2008).

Há ainda o Term Asset-Backed Securities Loan Facility (TALF) - linha (11) - que visava restabelecer os mercados de títulos securitizados. Criado em 25 de novembro de 2008, este instrumento só entrou efetivamente no balanço do Fed em 25 de março de 2009. Com ele, o Federal Reserve de Nova York tem como objetivo facilitar o crédito para pequenas empresas e famílias, incentivando a emissão de securities que têm como colaterais empréstimos para estudantes, financiamento de automóveis, dívidas de cartões de crédito etc.

Segundo Bernanke (2009c):

Relative to the Fed's short-term lending to financial institutions, the CPFF and the TALF are rather unconventional programs for a central bank to undertake. I see them as justified by the extraordinary circumstances in which we find ourselves and by the need for central bank lending practices to reflect the evolution of financial markets.

Logo, mesmo o presidente do Fed admite que os programas são "não convencionais" para um BC. O Fed agiu, de acordo com Buiter (2008b), como market maker of last resort; aceitando uma maior gama de colaterais e de instituições diversas. Essa concepção torna-se necessária em um sistema financeiro com muitos intermediários, no qual os bancos já não têm mais somente a função de "originar e distribuir".

A linha (10), Credit extended to $A I G$, e as linhas (14), (15) e (16), Net Portfolio holdings of Maiden Lane LLC, Maiden Lane LLC II e III, são os ativos criados para auxiliar a instituição privada AIG e para a compra do Bear Sterns pelo J. P. Morgan. Essas instituições foram socorridas para evitar o risco de contágio, ou seja, foram consideradas não somente "too big to fail", mas também 
"too interconnected to fail"19. Como AIG e Bear Sterns eram vistas como instituições importantes no mercado em que atuavam, a intervenção é justificada para evitar o risco sistêmico:

[...] dificuldades graves em bancos que participam de 'mercados relevantes' passam a suscitar a intervenção de 'última instância', mesmo quando esta não esteja nas 'regras do jogo' institucional, porque sua falência provocaria efeito dominó nesses mercados, com elevação do risco sistêmico (Farhi; Cintra, 2009, p. 287).

Bernanke (2009c) afirma que essas ações não são confortáveis para o Fed, uma vez que são mais arriscadas e só foram tomadas porque não havia alternativa viável. Em março de 2008, quando iniciou-se a operação de resgate ao Bear Sterns, os ativos estavam alocados na conta "Other Federal Reserves Assets" (linha 15). Em julho de 2008, foi criada uma LLC - Maiden Lane LLC - para deixar mais transparentes os valores ligados a essa compra. O montante apresentado no balanço, que em 29 de dezembro era de quase US\$27 bilhões, é o valor corrente de mercado dos ativos adquiridos do Bear Sterns, que eram de US\$ 30 bilhões em 14 de março de 2008, data do acordo conjunto com o J. P. Morgan de compra do Bear Sterns (Labonte, 2008).

Em setembro de 2008, a empresa AIG (American International Group) ameaça ir à falência e o Fed, então, emprestou diretamente US\$ 85 bilhões, a serem pagos em 2 anos. Esse primeiro empréstimo também aparecia na conta "Other Federal Reserves Assets". Em 28 de novembro de 2008, há uma mudança no balanço e esses valores passam a ser contabilizados na conta (9) - Credit extended to AIG. Além disso, nessa mesma data, foram criadas mais duas LLC Maiden Lane II e III (linhas (13) e (14), respectivamente). A primeira foi criada para comprar títulos lastreados em hipotecas residenciais de subsidiárias da AIG. A segunda tem por objetivo adquirir obrigações de dívida privada, sobre as quais a AIG emitiu contratos de swaps de crédito. A soma dessas três contas nos dá o valor total do socorro à AIG, que, em 29 de dezembro de 2008, era de aproximadamente US\$ 87 bilhões. Toda a ajuda à AIG somada foi de US\$150 bilhões (Cintra; Farhi, 2008).

Na linha (18) observa-se a conta "Other Federal Reserve Assets". Até dezembro de 2008, os maiores itens aí eram os ativos denominados em moeda

(19) Apesar da discordância sobre o socorro dos bancos de investimento dever-se ao fato de serem mais "too interconnected to fail" do que "too big to fail", Buiter (2009b) afirma que o que realmente importa é o tamanho da instituição, ou seja, a interconexão só irá importar se a instituição for grande. Em suas palavras: "All other activities currently undertaken by the banking sector and the shadow banking sector will be called investment banking activities. It might seem that, since the products, services and instruments created exclusively by the investment banking sector are not systemically important, these investment banks could be left to play by the normal rules of the market game, with little if any regulation. This is not the case because of a well-known problem: the 'too large to fail', 'too interconnected to fail', 'too complex to fail' and 'too international' to fail problem" (Buiter, 2009b, p. 30). 
estrangeira, que foram adquiridos através de operações de swap com outros bancos centrais, envolvendo troca de moedas. Esse programa começou em 12 de dezembro de 2007 e tinha por objetivo dar liquidez em dólares aos mercados internacionais e auxiliar outros BCs a aumentarem suas linhas de crédito $^{20}$. Nesta operação, o Fed trocava dólares pela moeda do $\mathrm{BC}$ estrangeiro à taxa de câmbio vigente no dia. $\mathrm{O}$ acordo previa que o $\mathrm{BC}$ estrangeiro recomprasse de volta a sua moeda em um prazo de 1 dia a 3 meses, com a mesma taxa de câmbio da transação inicial. $\mathrm{O}$ BC que usou a linha de swap pagava juros ao Fed, e este mantinha o montante em moeda estrangeira no próprio $\mathrm{BC}$ que tomou os dólares e não pagava juros.

A partir de 29 de janeiro de 2009, o Fed passou a apresentar as operações de swap em uma linha separada do ativo, chamada de "Central Bank Liquidity Swaps" - linha (17). Em 17 de dezembro de 2008, o valor corrente das operações de swap era de US\$ 582 bilhões $^{21}$, um valor muito expressivo, revelando a extensão mundial da crise $^{22}$. No entanto, essas operações diminuíram consideravelmente em 2009, chegando a US\$ 59 bilhões em 24 de setembro de 2009.

Há um instrumento criado em 11 de março de 2008 que se encontra fora do balanço, o "Term Securities Lending Facilities" (TSLF). No início de 2008, o mercado de fundos, no qual os dealers obtêm liquidez e fazem transações de compra e venda de títulos, ficaram travados. Uma grande preocupação neste mercado era o "risco da contraparte", uma vez que os emprestadores não sabiam ao certo a capacidade de pagamento do tomador. Neste cenário, um dealer podia ir à falência por não encontrar quem comprasse os títulos que tinha em seu poder. Assim, o Fed criou o TSLF, pelo qual os dealers podem emprestar títulos do Tesouro do Fed por 28 dias através de leilões, usando, como colaterais, títulos lastreados em hipotecas e títulos de dívida de agências governamentais. Essa ferramenta não tem impacto no balanço e, consequentemente, nas reservas, uma vez que é somente a troca de um título por outro temporariamente (Fleming;

(20) As linhas de swap foram autorizadas para os seguintes BCs: Reserve Bank of Australia, Banco Central do Brasil, Bank of Canada, Danmarks Nationalbank, Bank of England, European Central Bank, Bank of Japan, Bank of Korea, Banco de Mexico, Reserve Bank of New Zealand, Norges Bank, Monetary Authority of Singapore, Sveriges Riksbank e Swiss National Bank (http://www.federalreserve.gov/monetarypolicy/bst liquidityswaps.htm)

(21) http://www.treas.gov/press/international-reserve-position.html.

(22) Entre dezembro de 2007 e dezembro de 2008, o balanço do Banco Central Europeu (BCE) cresceu US\$ 174 bilhões, passando de US\$ 87 bilhões para US\$ 261 bilhões. Esse crescimento foi praticamente todo financiado pelas operações de swap do Fed, que foram de US\$ 172 bilhões com o BCE. O BCE, então, realizou operações de swap back-to-back com os bancos centrais nacionais da área do euro, que utilizaram os fundos resultantes em operações de fornecimento de liquidez em dólares dos EUA a contrapartes do Euro sistema sob a forma de operações reversíveis e swaps. Ou seja, aproximadamente $30 \%$ das operações de swap do Fed foram para o BCE (Fonte: Relatório Anual BCE - 2008). 
Hrung; Keane, 2009). Em 29 de dezembro de 2008, o total de títulos do Tesouro emprestados aos dealers era de aproximadamente US\$ 182 bilhões. Devido a pouca demanda pelo TSLF após junho de 2009, esse programa foi suspenso pelo Fed.

Por fim, chega-se, na linha (19), ao total de ativos - fatores "ofertando" reservas - do Fed. De julho de 2007 a dezembro de 2008, o seu montante aumentou em 2,5 vezes, de US\$ 912 bilhões para US\$ 2.293 bilhões. Essa mudança no período de auge da crise, conforme visto, não foi somente quantitativa. O Fed alterou radicalmente a estrutura de seus ativos, com venda maciça de títulos e novos programas de empréstimos e assistência a diversos setores e instituições. $\mathrm{O}$ objetivo do Fed com todos os programas era tentar colocar os mercados de volta em seu funcionamento normal e evitar as vendas "ansiosas" que tendem a pressionar os preços para baixo. A precificação dos títulos pelo Fed procurava dar, assim, um piso para o valor dos ativos, como os commercial papers (Chailloux et al., 2008).

Em setembro de 2009, o valor do ativo continua elevado, sendo de aproximadamente US\$ 2.200 bilhões. Os programas criados durante a crise vêm diminuindo seu valor, em parte devido ao início da recuperação da economia, o que possibilitou ao Fed uma nova recomposição do seu ativo com a compra de títulos. Percebe-se, na realidade, uma nova mudança de comportamento por parte do Fed, que está deixando de conceder empréstimos às instituições aos poucos e está incorporando os títulos lastreados em hipoteca em seu balanço. Entretanto, essa compra de títulos a partir de 2009 está sendo feita, ainda, com aumento das reservas bancárias, como será analisado a seguir.

\subsection{O financiamento das políticas: análise do passivo do balanço do Fed}

A Tabela 2 apresenta o passivo do Fed a partir do início da crise. As contas que mais se destacam são o papel-moeda em circulação, as contas do Tesouro e a conta de Reservas.

A linha (20) refere-se ao papel-moeda em circulação, que está em poder do público e dos bancos. O que surpreende nesta conta é o fato de não ter "explodido", dado o aumento no lado do ativo. Isso revela que os programas não foram financiados com o aumento do papel-moeda em poder do público ${ }^{23}$, já que, entre julho de 2007 e setembro de 2009, essa conta aumentou somente US\$ 93

(23) Apesar de essa conta ser denominada no passivo do Fed de "Currency in circulation", ela refere-se somente ao papel-moeda em poder do público e aos encaixes técnicos, e não ao papel-moeda em circulação, uma vez que não inclui os encaixes compulsórios e excedentes. 
bilhões. Esse valor seria considerável em tempos de normalidade, mas se torna insignificante ao observarmos o salto no ativo no mesmo período.

A linha (21) - U.S. Treasury, general account - é a conta do Tesouro no Fed. A linha (22) - U.S. Treasury, supplementary financing account - entrou no balanço em 25/09/2008 para complementar a primeira conta. O Tesouro emite e vende Treasury bills ao público no mercado primário e mantém o saldo recebido nesta conta $^{24}$. O saldo dessas contas, em 29 de dezembro, superava US\$ 400 bilhões. Se os programas de empréstimos não fossem criados, um aumento nessa conta teria o poder de absorver reservas, já que os bancos teriam que efetuar o pagamento das Treasury bills adquiridas pelo público. No entanto, como houve expansão do ativo, o Fed não permitiu essa queda nas reservas, pois os bancos usaram parte desse financiamento adicional e deixaram na conta do Tesouro. Dessa maneira, o Fed pôde aumentar o tamanho do seu balance sheet durante a crise, sem alterar o volume de papel-moeda em poder do público.

Todavia, o programa do Tesouro não foi suficiente para compensar todo o aumento no ativo e grande parte teve que ser alocada na conta de reservas (linha 24). Essa conta começou a aumentar substancialmente após setembro de 2008, quando cessa a venda de US Treasuries (Gráfico 6).

O fator decisivo para fazer com que a conta de reservas bancárias aumentasse dessa forma foi o anúncio, em outubro de 2008, de que o Fed iria começar a pagar juros nas reservas, tanto nas excedentes quanto nas compulsórias. A base monetária, que é a soma do dinheiro em circulação (linha 20) e das reservas, cresceu cerca de US\$ 777 bilhões entre setembro e dezembro de 2008. Este aumento foi concentrado principalmente nas reservas excedentes. A operação financeira feita pelo Fed de conceder empréstimos e, como contrapartida, aumentar a conta de reservas é, na verdade, criação de moeda. Segundo Taylor (2009b), a explosão das reservas não tem ligação com a decisão do Fed de diminuir a meta de taxa de juros para uma banda de $0-0,25 \%$ ao ano, uma vez que esta aconteceu meses após o crescimento das reservas - o que foi realmente devido à necessidade de financiar o aumento do balanço e os empréstimos.

The payment of interest on excess reserves will permit the Federal Reserve to expand its balance sheet as necessary to provide the liquidity necessary to support financial stability while implementing the monetary policy that is appropriate in light of the System's macroeconomic objectives of maximum employment and price stability $^{25}$.

(24) http://www.reuters.com/article/newIssuesNews/idUSN1751806420081117.

(25) http://www. federalreserve.gov/newsevents/press/monetary/20081006a.htm. 
Tabela 2

Balance Sheet do Federal Reserve (Passivo)

(em milhões de dólares)

\begin{tabular}{|c|c|c|c|c|c|c|c|c|}
\hline & 5/jul/07 & 4/out/07 & $3 / \mathrm{abr} / 08$ & $25 /$ set $/ 08$ & $28 /$ nov $/ 08$ & $29 / \mathrm{dec} / 08$ & $26 / \mathrm{mar} / 09$ & $24 /$ set/09 \\
\hline Currency in circulation (20) & 818.673 & 814.600 & 816.607 & 836.437 & 871.991 & 886.651 & 899.798 & 912.652 \\
\hline Reverse repurchase agreements & 32.209 & 34.542 & 41.061 & 90.673 & 99.761 & 88.317 & 66.427 & 70.803 \\
\hline Deposits with F.R. Banks, other than reserve balances & 10.877 & 12.518 & 13.471 & 187.138 & 511.018 & 426.994 & 267.313 & 257.390 \\
\hline U.S. Treasury, general account (21) & 4.117 & 5.645 & 6.013 & 5.175 & 17.355 & 118.058 & 56.198 & 50.907 \\
\hline Foreign official & 96 & 98 & 98 & 150 & 187 & 1.190 & 1.587 & 2.371 \\
\hline Service-related & 6.394 & 6.469 & 7.048 & 7.363 & 4.953 & 4.414 & 4.465 & 3.858 \\
\hline Other & 269 & 306 & 312 & 14.644 & 9.470 & 14.085 & 5.128 & 321 \\
\hline Other liabilities and capital & 39.754 & 40.689 & 43.680 & 46.361 & 54.368 & 76.190 & 55.584 & 59.530 \\
\hline Total $(23)+(24)$ & 912.100 & 906.862 & 919.671 & 1.248 .820 & 2.143 .636 & 2.293.371 & 2.107 .365 & 2.199 .876 \\
\hline
\end{tabular}

Fonte: Federal Reserve Statistical Release H.4.1, várias datas. Obs. N/A significa que a conta não existia na data. 
Gráfico 6

Treasury Securities em poder do FED e Nível das Reservas Bancárias julho de 2007 a dezembro de 2008

(em milhões de dólares)

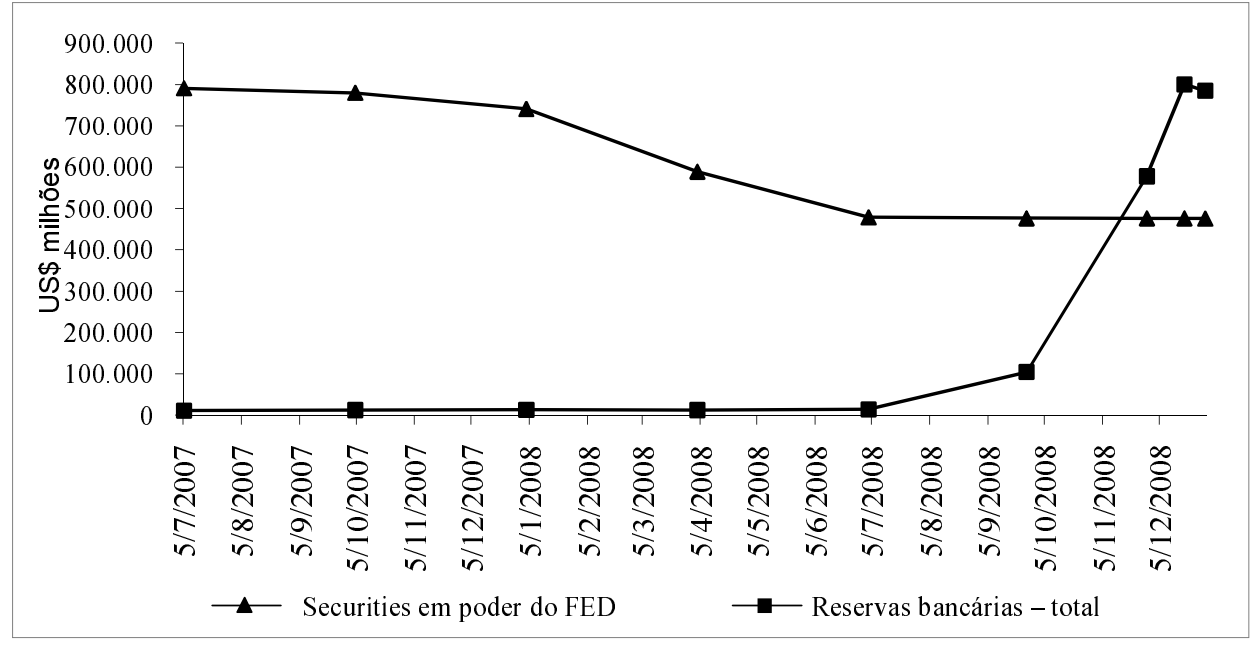

Fonte: Federal Reserve Statistical Release H.4.1, várias datas.

A decisão de pagar juros nas reservas tem por objetivo dar um piso para a taxa de juros dos federal funds, auxiliando a mesa de operações do Fed de Nova York a manter a meta para essa taxa. Os bancos, por se encontrarem subcapitalizados, também preferem manter ativos mais seguros em sua carteira, e a taxa de $0,25 \%$ ao ano é livre de risco e vista como a melhor oportunidade de investimento nas condições atuais do mercado.

Dessa forma, observa-se a incrível expansão do balance sheet do Fed, primeiramente a fim de conceder empréstimos e melhorar a liquidez dos mercados e posteriormente para aquisição de títulos do Tesouro e das agências Fannie Mae, Freddie Mac e Ginnie Mae. Essa expansão foi possível, em grande parte, graças ao aumento vertiginoso da conta de reservas bancárias.

\section{Considerações finais}

A ação do Fed antes e depois da crise subprime, sendo leniente com a formação da bolha no mercado imobiliário e extremamente intervencionista após o seu estouro, revela alguns aspectos interessantes do BC americano e mostra lições para a política monetária.

Devido à desregulamentação dos anos anteriores, o Fed não sabia o tamanho daquilo com que estava lidando, já que as operações com os produtos estruturados e derivativos eram feitas em mercados de balcão. O resultado foi o que vimos aqui: incerteza e dificuldade do Fed para lidar com o agravamento dos 
problemas, inclusive ao não socorrer o Lehman Brothers, e um aumento impressionante no seu balanço para conseguir conter a queda no preço dos ativos e a quebra de grandes bancos. O Fed é marcado por seu pragmatismo e atuou como prestamista de última instância sempre que necessário. A diferença nesta crise é que a atuação foi sem precedentes e os instrumentos tradicionais se esgotaram rapidamente, uma vez que a crise se iniciou em um mercado que não tinha acesso às linhas de liquidez do Fed e não tinha controle de órgãos regulatórios.

O Federal Reserve foi "minskyano" durante a crise, atuando como emprestador de última instância e usando tudo que tinha em mãos para socorrer o sistema financeiro. No entanto, não o foi durante o "boom", quando defendia a desregulamentação dos mercados. A ação ex-post do Fed exigiu maior criatividade em termos de operacionalização da política monetária para estabilizar o sistema e resgatou a necessidade de rediscussão do papel do BC.

Tanto antes quanto depois da crise, o Fed agiu para favorecer os interesses financeiros. Nas décadas anteriores, com regulação frouxa, compromisso com estabilidade de preços, taxas de juros baixas, liberdade aos bancos para criar produtos financeiros estruturados complexos; durante a crise, com o compromisso de fornecimento de liquidez sem limites. A desregulamentação dos anos 80 e 90 permitiu que as instituições financeiras se tornassem "too big to fail" e "too interconnected to fail", o que só fez aumentar o poder político e financeiro dos grandes bancos. A única tentativa de ir contra os interesses de Wall Street, com a negação de socorro ao Lehman Brothers, teve como resultado o aprofundamento da crise.

Simon Johnson, economista, ex-chefe do Fundo Monetário Internacional, coloca que, conforme a crise se aprofundava, os bailouts ficavam mais "criativos", sempre favorecendo os grandes grupos:

As the crisis has deepened and financial institutions have needed more help, the government has gotten more and more creative in figuring out ways to provide banks with subsidies that are too complex for the general public to understand. The first AIG bailout, which was on relatively good terms for the taxpayer, was supplemented by three further bailouts whose terms were more AIG-friendly. The second Citigroup bailout and the Bank of America bailout included complex asset guarantees that provided the banks with insurance at below-market rates. The third Citigroup bailout, in late February, converted government-owned preferred stock to common stock at a price significantly higher than the market price - a subsidy that probably even most Wall Street Journal readers would miss on first reading. And the convertible preferred shares that the Treasury will buy under the new Financial Stability Plan give the conversion option (and thus the upside) to the banks, not the government (Johnson, 2009, p. 7). 
Segundo Blanchard; Dell'Ariccia e Mauro (2010), o sucesso das intervenções do Fed anteriores à crise subprime deram a falsa impressão de que a política realizada era a correta e que os mercados realmente podiam se autoorganizar com a supervisão do BC, como foi o caso na falência do LTCM e da bolha ponto com:

The successful responses to the 1987 stock market crash, the Long-Term Capital Management (LTCM) collapse, and the bursting of the tech bubble reinforced the view that monetary policy was also well equipped to deal with the financial consequences of asset price busts (p. 7).

It may be even be that success in responding to standard demand and supply shocks, and in moderating fluctuations, was in part responsible for the larger effects of the financial shocks in this crisis (p. 10).

Mesmo a política de juros baixos do Fed durante a leniência tinha por objetivo proteger as instituições financeiras, já que era interessante para elas que a bolha imobiliária continuasse a inflar:

Because everyone was getting richer, and the health of the national economy depended so heavily on growth in real estate and finance, no one in Washington had any incentive to question what was going on. Instead, Fed Chairman Greenspan and President Bush insisted metronomically that the economy was fundamentally sound and that the tremendous growth in complex securities and credit-default swaps was evidence of a healthy economy where risk was distributed safely (Johnson, 2009, p. 6, grifo nosso).

Assim, tanto o Fed quanto Wall Street desejavam que os preços dos imóveis continuassem a subir.

Uma das principais lições da crise subprime e da inédita expansão do balance sheet do Fed é que o formato da regulação precisa ser repensado. A crise mostrou que o risco sistêmico é um fator que não pode ser ignorado e que as instituições desreguladas tendem a reduzir as margens de segurança e realizar operações arriscadas demais. Autores como Blanchard (Blanchard; Dell'Ariccia; Mauro, 2010) mostram que a política monetária também precisa ser repensada. $\mathrm{O}$ $\mathrm{BC}$ precisa utilizar todos os instrumentos que estão disponíveis, sendo a regulação o principal deles.

Além disso, a crise iniciada em 2007 renovou o debate sobre o papel dos bancos centrais na economia capitalista. O Novo Consenso priorizava a operacionalidade da política monetária para o controle dos preços e, para isso, o $\mathrm{BC}$ deveria deixar os mercados financeiros, que são eficientes na precificação dos ativos, livres e desregulados. O foco na inflação garantiria a estabilidade financeira. No entanto, a crise nos mostrou que bolhas e crises financeiras são inerentes ao sistema capitalista, e a administração da moeda parece envolver dimensões muito mais complexas do que o proposto pelo Novo Consenso. Uma 
das principais insuficiências nas orientações seguidas pelos $\mathrm{BCs}$ é a concepção restrita sobre os bancos. O Novo Consenso não leva em conta o fato de os bancos serem "criadores de moeda, concedendo crédito, e de intermediários financeiros, atuando como elo entre a esfera da circulação financeira e a esfera da circulação produtiva" (Freitas, 2005, p. 20). Com isso, estão constantemente submetidos à concorrência e à crescente busca pela valorização do capital e ampliação do lucro. Desta forma, inovam cada vez mais na administração de seus ativos e passivos, tendendo a subestimar riscos ao conceder crédito.

As insuficiências do pensamento dominante e da capacidade de ação do Banco Central tiveram papel decisivo para inibir a ação do Fed durante a formação da bolha, quando hesitou longamente sobre a sua identificação, inclusive sob a alegação de que seria impossível identificar corretamente o processo e atuar sobre ele de forma adequada com os instrumentos disponíveis.

A inovação nos instrumentos criados pelo Fed na sua atuação como emprestador de última instância demonstra o quanto o paradigma do Novo Consenso é limitado frente a processos financeiros. Para Aglietta (2004), o debate sobre princípios monetários estava encerrado desde os anos 1980, quando o pensamento econômico dominante passou a discutir somente a operacionalidade da política monetária e tratou de esquecer a complexidade dos problemas financeiros, em especial a instabilidade inerente ao sistema. Buiter (2009a) coloca que:

Both the New Classical and New Keynesian complete markets macroeconomic theories not only did not allow questions about insolvency and illiquidity to be answered. They did not allow such questions to be asked (p. 2).

Charles Goodhart, who was fortunate enough not to encounter complete markets macroeconomics and monetary economics during his impressionable, formative years, but only after he had acquired some intellectual immunity, once said of the Dynamic Stochastic General Equilibrium approach which for a while was the staple of central banks' internal modeling: "It excludes everything I am interested in". He was right. It excludes everything relevant to the pursuit of financial stability (p. 7).

A crise em si não foi causada pelas crenças do Novo Consenso, mas mostrou as suas falhas. Não há como considerar, dentro deste aparato teórico, a instabilidade inerente da economia capitalista, uma vez que os próprios pressupostos são incompatíveis.

A virulência da crise e o tamanho dos processos financeiros dos anos recentes reforçam a necessidade de avançar nas formulações teóricas e operacionais de inspiração pós-keynesiana para a atuação dos bancos centrais para que sejam mais abrangentes e levem em conta os novos desafios da era das finanças. Além de promover o pleno emprego e garantir a estabilidade de preços, 
um $\mathrm{BC}$ deve ter o papel primordial de assegurar a estabilidade financeira e ter poderes de intervenção claros em seu estatuto, tanto no caso de instituições que estejam tomando riscos excessivos quanto na formação de processos especulativos generalizados. Rediscutir metas, objetivos e instrumentos dos BCs tornou-se uma necessidade imediata.

\section{Referências bibliográficas}

AGLIETTA, M. Macroeconomia financeira. São Paulo: Edições Loyola, 2004.

BERNANKE, B.; GERTLER, M. Monetary policy and asset price volatility. Cambridge: NBER, 2000. (Working Paper Series, n. 7559). Disponível em: http://www.nber.org/papers/w7559. Acesso em: 3 out. 2008.

. Liquidity Provision by the Federal Reserve. Speech at the Federal Reserve Bank of Atlanta Financial Markets Conference, Sea Island, Georgia. 13th May de 2008a. Disponível em: http://www.federalreserve.gov/newsevents/speech/bernanke20080513.htm. Acesso em: 6 out. 2008 .

. U.S. financial markets. Speech before the Committee on Banking, Housing, and Urban Affairs, U.S. State Senate. $23^{\text {rd }}$ Sept, 2008b. Disponível em: http://www.federalreserve.gov/newsevents/testimony/bernanke20080923a1.htm. Acesso em: 14 jan. 2009.

. The crisis and policy response. Speech at the Stamp Lecture, London School of Economics. London: 13 ${ }^{\text {th }}$ Jan. 2009a. Disponível em: http://www.federalreserve.gov/newsevents/speech/bernanke20090113a.htm. Acesso em: 22 fev. 2008.

- Federal Reserve policies to ease credit and their implications for the Fed's Balance Sheet. Speech at the National Press Club Luncheon, National Press Club. Washington: 18 ${ }^{\text {th }}$ Feb. 2009b. Disponível em: http://www.federalreserve.gov/newsevents/speech/bernanke20090218a.htm. Acesso em: 2 abr. 2009.

. The Federal Reserve's Balance Sheet. Speech at the Federal Reserve Bank of $\overline{\text { Richmond }} 2009$ Credit Markets Symposium, Charlotte, North Caroline. $3^{\text {rd }}$ Apr. 2009c. Disponível em: http://www.federalreserve.gov/newsevents/speech/bernanke20090403a.htm. Acesso em: 7 abr. 2009.

BLANCHARD, O.; DELL'ARICCIA, G.; MAURO, P. Rethinking macroeconomic policy. Washington, DC: International Monetary Fund, $12^{\text {th }}$ Feb. 2010. (IMF Staff Position Note).

BLINDER, A.; REIS, R. Understanding the Greenspan Standard. In: The Greenspan era: lessons for the future. Jackson Hole: p. 11-96, 2005. Disponível em: http://www.kansascityfed.org/publicat/sympos/2005/pdf/Blinder-Reis2005.pdf. Acesso em: 25 set. 2008.

BORDO, M. D.; JEANNE, O. Monetary policy and asset prices: does "benign neglect" make sense? 2002. IMF Working Paper. N. 02/225, Disponível em: http://www.imf.org/external/pubs/ft/wp/2002/wp02225.pdf. Acesso em: 25 set. 2008. 
BUITER, W. H. Central Banks and financial crises. 2008a. (Jackson Hole Symposium Papers). Disponível em: http://www.kc.frb.org/publicat/sympos/2008/Buiter.08.16.08.pdf. Acesso em: 25 out. 2008.

. The Fed as market maker of last resort: better late than never. Financial Times. $12^{\text {th }}$ Mar. 2008b. Disponível em: http://blogs.ft.com/maverecon/2008/03/the-fedas-market-maker-of-last-resort-better-late-than-never/\#axzz1 VU3W2XmR/. Acesso em: 18 dez. 2008.

The unfortunate uselessness of most 'state of the art' academic monetary economics. $3^{\text {rd }}$ Mar. 2009a. Disponível em: http://blogs.ft.com/maverecon/2009/03/theunfortunate-uselessness-of-most-state-of-the-art-academic-monetaryeconomics/\#axzz1VU3W2XmR. Acesso em: 13 jul. 2009.

. Lessons from the global financial crisis for regulators and supervisors. $25^{\text {th }}$ Anniversary Workshop of the Advanced Studies Program of the IFW: The Global Financial Crisis: Lessons and Outlook. Kiel: 8/9 May 2009b. Disponível em http://www.nber.org/ wbuiter/asp.pdf. Acesso em: 1 out. 2009.

CARVALHO, F. J. C. Inovação financeira e regulação prudencial: da regulação da liquidez aos Acordos da Basileia. In: SOBREIRA, R. (Org.). Regulação financeira e bancária. São Paulo: Atlas, 2005.

CECCHETTI, S. G. Monetary policy and the financial crisis of 2007-2008. CEPR Policy Insight, London, n. 21, Apr. 2008a. Disponível em: http://www.cepr.org/pubs/PolicyInsights/PolicyInsight21.pdf. Acesso em: 20 abr. 2009.

. Crisis and responses: the Federal Reserve in the early stages of the financial crisis. Journal of Economic Perspectives, Pittsburgh, PA, v. 23, n. 1, p. 51-75, Winter 2009.

CHAIllouX, A. et al. Central Bank response to the 2007-2008 financial market turbulence: experiences and lessons drawn. Sept. 2008. (IMF Working Paper, n. 08/210). Disponível em: http://www.imf.org/external/pubs/ft/wp/2008/wp08210.pdf. Acesso em: 20 jan. 2008.

CINTRA, M. A. M. A dinâmica dos mercados financeiros globais e as contradições da política monetária americana frente à globalização financeira. Ensaios FEE, Porto Alegre, v. 21, n. 2 , p. $183-206,2000$.

; FARHI, M. A crise financeira global e o global shadow banking system. Novos Estudos CEBRAP, São Paulo, n. 92, p. 35-55, nov. 2008.

COLANDER, D. et al. The financial crisis and the systemic failure of academic economics. 2008. Disponível em: http://economistsview.typepad.com/economistsview/2009/02/the-financial-crisis-and-thesystemic-failure-of-academic-economics.html. Acesso em: 10 mar. 2009.

CROTTY, J.; EPSTEIN, G. The costs and contradictions of the lender-of-last-resort function in contemporary capitalism: the sub-prime crises of 2007-2008. Draft, Oct. 2008.

FARHI, M.; CINTRA, M. A. M. A arquitetura do sistema financeiro internacional contemporâneo. Revista de Economia Política, São Paulo, v. 29, n. 3(115), p. 274-294, jul./set. 2009. 
FED. The implementation of monetary policy. 9. ed. In: THE FEDERAL Reserve System: purposes and functions. Jun. 2005a.

- Minutes of FOMC Meetings (several). 2002 e 2005b. Disponível em http://www.federalreserve.gov/monetarypolicy/fomccalendars.htm.

Monetary policy releases (several). 2008. Disponível em: http://www.federalreserve.gov/newsevents/press/monetary/2008monetary.htm.

- Federal Reserve System Monthly Report on Credit and Liquidity Programs

and the Balance Sheet. Sept. 2009. Disponível em: http://www.federalreserve.gov/monetarypolicy/files/monthlyclbsreport200909.pdf. Acesso em: 10 out. 2009 .

FISCHER, S. On the need for an international lender of last resort. Journal of Economic Perspectives, Pittsburgh, PA, v. 13, n. 4, p. 85-104, Fall 1999.

FLEMING, M. J.; HRUNG, W. B.; KEANE, F. M. The term securities lending facility: origins, design and effects. Federal Reserve Bank of New York Current Issues in Economics and Finance, New York, v. 15, n. 2, Feb. 2009.

FREITAS, M. C. P. Racionalidade da regulamentação e supervisão bancária: uma interpretação heterodoxa. In: SOBREIRA, Rogério (Org.). Regulação financeira e bancária. São Paulo: Atlas, 2005.

; CINTRA, M. A. M. Inflação e deflação de ativos a partir do mercado imobiliário americano. Revista de Economia Política, São Paulo, v. 28, n. 3 (111), p. 414433, jul./set. 2008.

GAVIN, W. T. More money: understanding recent changes in the monetary base. Federal Reserve of St. Louis Review, St. Louis, v. 91, n. 2, p. 49-59, Mar./Apr. 2009.

GREENSPAN, A. Opening remarks. In: RETHINKING Stabilization Policy. Jackson Hole: 2002. p. 1-10. Disponível em: http://www.kc.frb.org/publicat/sympos/2002/pdf/S02Greenspan.pdf. Acesso em: 26 mar. 2008.

. Opening remarks. In: THE GREENSPAN era: lessons for the future. Jackson Hole: 2005. p. 1-10. Disponível em: http://www.kc.frb.org/publicat/sympos/2005/PDF/Greenopening2005.pdf. Acesso em: 28 mar. 2009.

GOODHART, C. Why do banks need a Central Bank. In: THE CENTRAL Bank and the financial system. Cambridge: MIT Press, 1987.

HILSENRATH, J.; SOLOMON, D.; PALETTA, D. Crise colocou em confronto Fed e Tesouro. Valor Econômico, São Paulo, 11 nov. 2008. Disponível em: http://www.valoronline.com.br/?impresso/financas/93/5258704/0/crise-colocou-emconfronto--fed-e--tesouro. Acesso em: 15 nov. 2008.

JOHNSON, S. The quiet coup. The Atlantic Online, May 2009. Disponível em: http://www.theatlantic.com/magazine/archive/2009/05/the-quiet-coup/7364/. Acesso em: 27 fev. 2010.

LABONTE, M. Financial Turmoil: Federal Reserve Policy Responses. CRS Report for Congress, $23^{\text {rd }}$ Oct. 2008. 
MINSKY, H. The financial instability hypothesis: an interpretation of Keynes and an alternative to "standard" theory. In: CAN "it" happen again? Essays on instability and finance. Armonk, New York: M.E. Sharpe, 1982a. p. 59-70.

The financial instability hypothesis: a restatement. In: CAN "it" happen again? Essays on instability and finance. Armonk, New York: M.E. Sharpe, 1982b. p. 90-116.

. Stabilizing an unstable economy. New Haven: Yale University Press, 1986.

. Back from the Brink. Interview in Challenge. Jan./Feb. 1988. p. 22-28.

MISHKIN, F. Financial instability and the Federal Reserve as a liquidity provider speech at the Museum of American Finance Commemoration of the Panic of 1907. New York: $26^{\text {th }}$ Oct. $2007 \mathrm{a}$.

p. 1-7, 2007b.

Systemic risk and the international lender of last resort. BIS Review, 109,

TAYLOR, J. B. Housing and monetary policy. In: HOUSING finance and monetary policy. Jackson Hole, 2007. p. 463-476. Disponível em: http://www.kc.frb.org/publicat/sympos/2007/pdf/Taylor_0415.pdf. Acesso em: 20 mar. 2008.

. The financial crisis and the policy responses: an empirical analysis of what went wrong. Cambridge: NBER, Jan. 2009a. (NBER Working Paper, n. 14631).

. Monetary policy and the recent extraordinary measures taken by the Federal Reserve. Testimony before the Committee on Financial Services, US House of Representatives, $26^{\text {th }}$ Feb. 2009b.

TYMOIGNE, E. Asset prices, financial fragility, and Central Banking. The Levy Economics Institute of Bard College, Jun. 2006. (Working paper, n. 456).

WRAY, L. R. The Fed and the New Monetary Consensus: the case for rate hikes, part two. Public Policy Brief, The Levy Economics Institute of Bard College, n. 80, 2004. 